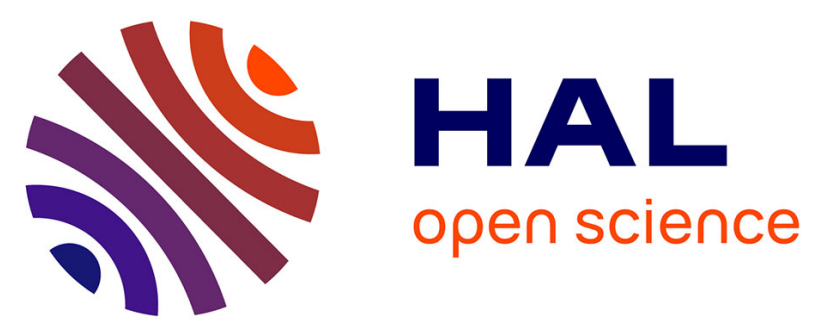

\title{
Correlation between the interfacial ion dynamics and charge storage properties of poly(ortho-phenylenediamine) electrodes exhibiting high cycling stability.
}

El Mahdi Halim, Rezan Demir-Cakan, Hubert Perrot, Mama El Rhazi, Ozlem Sel

\section{To cite this version:}

El Mahdi Halim, Rezan Demir-Cakan, Hubert Perrot, Mama El Rhazi, Ozlem Sel. Correlation between the interfacial ion dynamics and charge storage properties of poly(ortho-phenylenediamine) electrodes exhibiting high cycling stability.. Journal of Power Sources, 2019, 438, pp.227032. 10.1016/j.powsour.2019.227032 . hal-02439102

\section{HAL Id: hal-02439102 https://hal.science/hal-02439102}

Submitted on 4 Jan 2021

HAL is a multi-disciplinary open access archive for the deposit and dissemination of scientific research documents, whether they are published or not. The documents may come from teaching and research institutions in France or abroad, or from public or private research centers.
L'archive ouverte pluridisciplinaire HAL, est destinée au dépôt et à la diffusion de documents scientifiques de niveau recherche, publiés ou non, émanant des établissements d'enseignement et de recherche français ou étrangers, des laboratoires publics ou privés. 


\title{
Correlation between the interfacial ion dynamics and charge storage properties of poly(ortho-phenylenediamine) electrodes exhibiting high cycling stability
}

\author{
El Mahdi Halim ${ }^{\dagger,}$, Rezan Demir-Cakan ${ }^{\S, ¥}$, Hubert Perrot $^{\dagger}$, Mama El Rhazi $^{*}$, ,Ozlem Sel $^{*}{ }^{\dagger}$
}

† Sorbonne Université, CNRS, Laboratoire Interfaces et Systèmes Electrochimiques, LISE, 75005 Paris, France

¥ University of Hassan II of Casablanca, Faculty of Sciences and Technology, Laboratory of Materials, Membranes and Environment -BP 146, 20650 Mohammedia, Morocco

$\S$ Institute of Nanotechnology, Gebze Technical University, 41400 Gebze, Kocaeli, Turkey

${ }^{¥}$ Department of Chemical Engineering, Gebze Technical University, 41400 Gebze, Kocaeli, Turkey

* Corresponding authors: Email: ozlem.sel@upmc.fr

Email: elrhazim@hotmail.com

\begin{abstract}
An integrated electrogravimetric study based on electrochemical quartz crystal microbalance (EQCM) unravels the interfacial ion transfer phenomena of the poly(orthophenylenediamine) (PoPD) thin film electrodes. Through a methodology coupling QCM with electrochemical impedance spectroscopy (ac-electrogravimetry), our work indicates that charge compensation process of PoPD in aqueous electrolytes (in acidified $\mathrm{NaCl}$ ) occurs with the participation of multiple species, each playing a role at different temporal scales. The PoPD films are tested in a 2 electrode Swagelok cell in which $\mathrm{Zn}$ is used as both reference and counter electrodes and exhibit excellent stability over 8000 cycles with a relatively high specific capacitance of about $110 \mathrm{~F} \cdot \mathrm{g}^{-1}$ at $30 \mathrm{C}\left(0.63 \mathrm{~mA} \cdot \mathrm{cm}^{-2}\right)$ current density. The high rate capability and the excellent cycling stability of the PoPD electrodes are correlated to the electrolyte composition and the significant role of $\mathrm{H}^{+}$to the charge compensation process is unravelled, which is made possible with coupled electrogravimetric methods of our study. By determining the interfacial flux dynamics and as well as the relative proportions of species transferred at the electrode/electrolyte interface, our results contribute to the understanding of the charge-discharge process of PoPD polymer, yet underexplored but emerging as a pseudo-capacitive electrode material.
\end{abstract}

KEYWORDS: poly(ortho-phenylenediamine); pseudo-capacitors; cycling stability; interfacial ion transfer; electrochemical quartz crystal microbalance; electrogravimetric impedance (acelectrogravimetry) 


\section{INTRODUCTION}

Conducting polymers (CPs) have been extensively investigated and solicited in various fields of applications, such as in electrocatalysis, biosensors and microelectronics technology [1-4]. In energy storage, these pseudo-capacitive materials are regarded as prospective electrode component considering their salient features such as high electrical conductivity and high redox activity, as well as their relatively low cost and ease of synthesis [5-8].

Specifically, polyaniline (PANI), polypyrrole (PPy), polythiophene (Pth) and their derivatives have extendedly been studied as electrode materials due to their high specific capacitance which is substantially higher than those of the conventional carbon-based electrodes and comparable to pseudocapacitive metal oxides $[9,10]$. However, their cycling stability is a major impediment that limits their practical application. For example, pristine PANI, PPy and Pth based pseudocapacitive electrodes have been reported to lose substantial amount of their capacitance after about 1000 cycles and there is a lack of information about the electrode stability beyond this threshold [11].

Several methods have been used to enhance the cycling stability of conducting polymer based electrodes. It was postulated that the electrochemical performance is affected by various factors, including synthetic method, dopant ion, substrate and the morphology of the conducting polymer [5]. Therefore, the strategies to enhance the cycling stability include (i) encapsulation of the conducting polymer in inorganic networks, such as titania nanotubes [12], (ii) surface coating such as with Nafion [13] and (iii) doping with organic molecules such as para-toluenesulfonate [14]. For instance, the phytic acid (PA) doped polypyrrole (PPy) has been reported to retain its specific capacitance for about 4000 cycles on specific substrates [15]. Regarding the efforts on the morphology, PPy nanowire arrays have been shown that they retain $70 \%$ of the initial capacitance after several hundred cycles and are advantageous over disordered nanowire 
networks or conventional films [16]. However, the fabrication time, the toxicity and the cost of the dopant materials limit the practical application of these synthesis methods [11]. Additionally, despite the multiple efforts, it remains still challenging to reach cycling stability more than $\sim 1000$ cycles, except from limited number of reports providing information about the long term electrode stability. For example, Li et al. has shown that the deposition of a thin carbonaceous shell ( $\sim 5 \mathrm{~nm})$ onto the $\mathrm{CP}$ electrode drastically improves the charge/discharge cycling stability i.e., $\sim 95$ and $\sim 85 \%$ capacitance retention after 10000 cycles, for PANI and PPy, respectively [11]. Similarly, the reduced graphene oxide layer has been employed as a protective layer on PANI to tackle with the cycling stability issue and $75.5 \%$ of original capacitance has been maintained up to 10000 cycles [17].

While substantial research efforts evolve in the direction of protecting the $\mathrm{CP}$ based electrodes especially to alleviate swelling and shrinking during cycling and thus to enhance the cycling stability, one other path is to scrutinize the structural effects by investigating the derivatives of the most researched conducting polymers. In this context, aromatic diamine polymers such as para, ortho and meta-phenylenediamine (PD) have received great attention due to the active free amino and imino groups present in their structure, which provide structural modification possibility [18]. They have been the subject of several studies in the past decade in view of their attractive (electro)chemical properties, $[19,20]$ and also have been receiving attention as pseudocapacitive CP electrodes (ortho-,[21] and para-,[22]). In addition to their direct intervention as electrode materials, poly ortho-phenylenediamine (PoPD) polymers doped with glycine was carbonized to obtain nitrogen and oxygen doped hallow carbon spheres for supercapacitor applications [23]. Regarding the synthesis, the electropolymerization of orthophenylenediamine (oPD) in acidic, alkaline and neutral aqueous solutions has been examined and electrochemical quartz crystal microbalance (EQCM) has been used to investigate the subtleties 
of polymerization mechanism and the subsequent electrochemical activity of the resulting electrodes $[19,24,25]$.

As an extension to the previous studies $[19,24,25]$ and due to the developing interest in the PoPD type $\mathrm{CP}$ as pseudocapacitive electrodes, a thorough investigation of the electrochemical charge storage behaviour becomes deservedly necessary. It is also noted that, to the best of our knowledge, there is no study describing the interfacial ion flux (insertion/deinsertion and/or electroadsorption/desorption of ions) with the exact identification of the intervening (non)ionic species together with their dynamics of transfer at the PoPD film/electrolyte interfaces. It is wellknown that interfacial ion flux dynamics constitute an important part of the operating principle of super- and pseudo-capacitors, therefore the correlation of this fundamental understanding to the charge storage properties of poly(ortho-phenylenediamine) thin film electrodes is rather significant but requires specific characterization tools.

A marked improvement in understanding the charge storage mechanisms has been obtained thanks to recent progress with electrogravimetric methods (EQCM and EQCM with dissipation monitoring) [26-28]. Besides, the complex character of the electrode mass changes, the viscoelastic properties of the electrodes and also possibly formed solid electrolyte interface (SEI) layer can be investigated using multiharmonic EQCM with dissipation monitoring (EQCM-D) $[29,30]$. It can offer opportunities to identify the impact of several parameters (nature of the electrolytes, ions, binder...) on the structural change of the electrodes.

In addition to these developments in the use of EQCM based methods in the energy storage domain, here, a non-conventional complementary technique, the so-called ac-electrogravimetry has been proposed to unveil the mechanisms of the ionic exchange process [31-33]. It has been demonstrated that highly relevant and complementary information to the classical EQCM can be 
obtained: (i) kinetics and identification of species transferred between the electrode and the electrolyte, (ii) separation of the different contributions related to the charged and non-charged species involved in the electrochemical processes, (iii) identification of species transferred in opposite flux directions provided that their kinetics are sufficiently different and (iv) variation of the relative concentrations of the species inside the examined material [34-38]. The originality of this method is its ability to discriminate between the interfacial transfer of cations, anions and solvent molecules involved (directly or indirectly) in the charge compensation process which is ultimately related to their charge storage performance.

Thus, we report here on the investigation of the ion exchange mechanisms in PoPD pseudocapacitive electrode. The electropolymerization of oPD was carried out in acidic medium. Thereafter, the redox transformations and the ionic flux mechanisms were investigated in aqueous $\mathrm{NaCl}$ electrolyte via EQCM and ac-electrogravimetry. Several parameters were considered to explain the redox behaviour of PoPD film, such as the nature and the dynamic of the ions transfer at the PoPD film/electrolyte interface. To correlate these fundamental understandings to the performance of the electrode, the cycling stability of the thin PoPD film electrode was tested in two-electrode Swagelok-type cell resulting excellent cycling stability for more than 8000 cycles with $\sim 110 \mathrm{~F} \cdot \mathrm{g}\left(11 \mathrm{mF} \cdot \mathrm{cm}^{2}\right)$ capacitance at $30 \mathrm{C}$. These performances are relevant to the recent developments in the field of thin conducting polymer electrodes for micro energy storage devices [39-41].

\section{EXPERIMENTAL PART}

2.1. Electrode Preparation. Electrochemical polymerization of oPD was performed on the gold electrode $\left(0.2 \mathrm{~cm}^{2}\right)$ of quartz crystal resonators (9 MHz-AWS, Valencia, Spain) and on graphite plates $\left(\sim 1 \mathrm{~cm}^{2}\right)$ for the electrogravimetric studies and for the tests in two-electrode Swagelok 
cells, respectively. Specifically, oPD monomer (1,2-diaminobenzene, Sigma-Aldrich) (5 mM) dissolved in $\mathrm{H}_{2} \mathrm{SO}_{4}$ solution $(0.1 \mathrm{M})$ was electropolymerized using cyclic voltammetry $(\mathrm{CV})$. This step was also followed through EQCM measurements i.e. when quartz crystal resonators were used as substrates. The mass of the deposited polymer was evaluated by measuring the resonant frequency of the quartz crystal $(\Delta f)$, before and after the electropolymerization, which was then converted to the mass change $(\Delta m)$ by the Sauerbrey equation $\left(\Delta f_{m}=-k_{s^{*}} \Delta m\right)$ where $k_{s}=16.31 \times 10^{7} \mathrm{~Hz} \mathrm{~g}^{-1} \mathrm{~cm}^{2}$ is the experimental sensitivity coefficient $[42,43]$.

2.2. Electrode Characterization. The morphology and the thickness of the PoPD films were analysed using a field emission gun scanning electron microscope (FEG-SEM, Zeiss, Supra 55).

2.3. Electrochemical Characterization of the electrodes. Electrochemical quartz crystal microbalance $(\mathrm{EQCM})$ measurements were carried out in aqueous $0.5 \mathrm{M} \mathrm{NaCl}$ solution and $\mathrm{pH}$ was adjusted to $\mathrm{pH}=2$ by the addition of $\mathrm{HCl}$. A three-electrode cell was employed, in which, a platinum grid was used as counter electrode, $\mathrm{Ag} / \mathrm{AgCl}(3 \mathrm{M} \mathrm{KCl}$ saturated with $\mathrm{AgCl})$ as reference electrode and a gold-patterned quartz substrates operating at $9 \mathrm{MHz}$ as working electrode. The $a c$-electrogravimetry measurements were performed using a four-channel frequency response analyser (FRA, Solartron 1254) and a lab-made potentiostat (SOTELEMPGSTAT). The QCM was used under dynamic regime, the working electrode was polarized at a selected potential, and a sinusoidal small amplitude potential perturbation was applied. The frequency range was between $63 \mathrm{kHz}$ ad $10 \mathrm{mHz}$. The mass change, $\Delta m$, of the quartz electrode was measured simultaneously with the ac response, $\Delta I$, of the electrochemical system. The resulting signals were sent to a four-channel FRA, which permitted the electrogravimetric transfer function $(\mathrm{TF})$ and the electrochemical impedance to be simultaneously obtained at a given potential. The main TFs (electrogravimetric $\operatorname{TF}\left(\frac{\Delta m}{\Delta E}(\omega)\right)$ ), classical impedance $\left(\frac{\Delta E}{\Delta I}(\omega)\right)$ and 
charge/potential TF $\left(\frac{\Delta q}{\Delta E}(\omega)\right)$ (derived from impedance)) were fitted through the theoretical expressions given in Equations 1-4. Providing that all the TFs including cross and partial TFs (detailed in Refs. [31, 32, 34, 36-38]) were fitted with the same set of parameters (where a good agreement between the experimental and the theoretical functions in terms of both the shape and the frequencies are achieved), then these parameters $\left(M_{i}, K_{i}\right.$ and $\left.G_{i}\right)$ are considered as unique. Galvanostatic charge/discharge (GCD) measurements were performed by a classical twoelectrode Swagelok-type cell, where zinc metal was used as both reference and counter electrode and PoPD deposited on graphite plate as working electrode. Zn metal (-0.76 V vs SHE) is chosen among the other counterparts to be employed as electrode material in aqueous medium, as its reduction potential falls within the water stability window. The glass fiber separators (Whatman $\mathrm{GF} / \mathrm{C}$ with areal weight and thickness of $4.7 \mathrm{mg} / \mathrm{cm}^{2}$ and $185 \mu \mathrm{m}$, respectively) are used for the measurements in Swagelok cells. GCD tests were conducted in an aqueous electrolyte containing $1 \mathrm{M} \mathrm{NaCl}(\mathrm{pH}=2)$ cycled at $30 \mathrm{C}$ current density that is equivalent to $0.63 \mathrm{~mA} \cdot \mathrm{cm}^{-2}$.

\section{RESULTS AND DISCUSSION}

\subsection{Electrochemical synthesis and morphological characterization of the PoPD.}

Electrochemical synthesis of the PoPD thin film was performed by CV starting from the oPD monomer. Figure 1a shows the CV curves during the formation of the PoPD thin film on the gold electrode of the quartz crystal. This specific substrate was chosen to be able to perform electrogravimetric studies thereafter (Figure 1b). During the first scan, an oxidation peak with a large current appears at about $+0.62 \mathrm{~V}$ vs $\mathrm{Ag} / \mathrm{AgCl}$, indicating the oxidation of oPD monomer. In the subsequent scans, the current value of this first anodic peak significantly decreases, whereas an increase in the current value of the redox peaks at $E_{\text {cathodic }}=-0.16 \mathrm{~V}$ and Eanodic $=-0.12 \mathrm{~V} v \mathrm{~s}$ $\mathrm{Ag} / \mathrm{AgCl}$ is evident. The appearance of another redox peak is also noted at around $0 \mathrm{~V} v \mathrm{~s}$ 
$\mathrm{Ag} / \mathrm{AgCl}$. Then, these two redox peaks (in the range of $0.2 \mathrm{~V}$ to $-0.4 \mathrm{~V}$ vs $\mathrm{Ag} / \mathrm{AgCl}$ ) are merged resulting in a pair of large anodic and cathodic peaks as observed for the $200^{\text {th }}$ cycle of the CV curve presented in Figure 1a. These observations are in agreement with earlier electrodeposition studies of PoPD thin films $[25,44]$. The proposed mechanism of the electropolymerization of

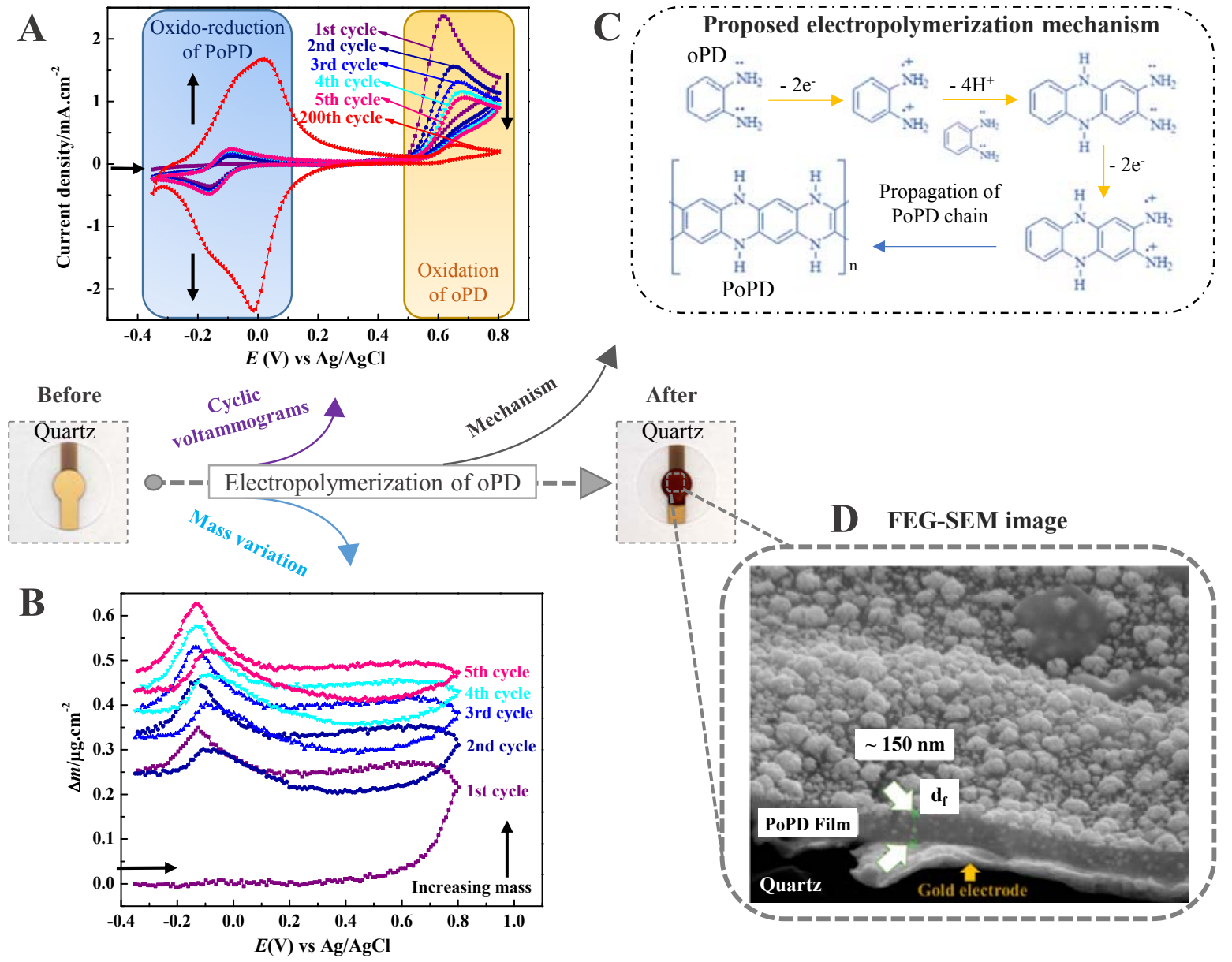

Fig. 1. PoPD thin film synthesis by electropolymerization on a gold electrode of a quartz resonator in an aqueous solution of $\mathrm{H}_{2} \mathrm{SO}_{4}(0.1 \mathrm{M})$ and oPD $(5 \mathrm{mM})$. (a) $\mathrm{CV}$ Curves, (b) corresponding mass variations $(\Delta m)$ obtained by EQCM at a scan rate of $50 \mathrm{mV} \cdot \mathrm{s}^{-1},(\mathbf{c})$ proposed electropolymerization mechanism and (d) FEG-SEM image of a PoPD thin film on the gold electrode of a quartz resonator after $200 \mathrm{CV}$ cycles. 
oPD (Figure 1c) starts by the oxidation of the monomers to give radical cations. These cationic radicals react chemically together to produce dimers which can be further oxidized. Then, the oligomer cations or bications propagates to give either a linear polymer chain or cyclic polymers with ladder structures through the polymerization of the oxidized products $[18,19,45,46]$.

The frequency variations of the gold coated quartz resonator during the electropolymerization was converted to the corresponding mass variations (using Sauerbrey equation [42]) as shown in Figure 1b. At the beginning of the electropolymerization, during the anodic sweep, the $\Delta m$ of the electrode is virtually constant until $0.5 \mathrm{~V}$, after which a significant $\Delta m$ increase is observed. It is important to note that this potential range corresponds to the oxidation of the oPD monomer and/or the formation of dimer and oligomers on the gold electrode of the quartz resonator. In the cathodic sweep, there is no significant mass variation until $0.1 \mathrm{~V} v \mathrm{Ag} / \mathrm{AgCl}$ then, $\Delta m$ increases and reaches a maximum at about $-0.1 \mathrm{~V}$ vs $\mathrm{Ag} / \mathrm{AgCl}$, followed by a decrease up to $-0.4 \mathrm{~V}$ corresponding to the redox processes of newly formed PoPD film. These observations are in agreement with earlier reports [19]. A continuous mass increase was observed (only the first 5 cycles are shown in Figure 1b) which resulted in $22 \mu \mathrm{g} . \mathrm{cm}^{-2}$ of total mass deposition after typically $200 \mathrm{CV}$ cycles. Figure 1d shows the FEG-SEM image of a representative PoPD film deposited on the gold electrode of a quartz resonator. The figure reveals the full coverage of the gold surface with the PoPD film which has an average thickness of $\sim 150 \mathrm{~nm}$. The electrogravimetric response of the resulting PoPD film will be investigated below at the section 3.2.1. One can consider that a pure gravimetric response can be obtained as the film is acoustically thin $(\sim 150 \mathrm{~nm})[47]$.

\subsection{Electrogravimetric characterization of charge storage behavior.}

\subsubsection{Electrochemical Quartz Crystal Microbalance (EQCM).}


Figure 2 shows the EQCM responses of PoPD thin films in $0.5 \mathrm{M} \mathrm{NaCl}$ solution with different $\mathrm{pH}$ values. In acidic media $(\mathrm{pH}=2)$, the PoPD shows a typical redox behavior between $-0.4 \mathrm{~V}$ and $0.2 \mathrm{~V}$ vs $\mathrm{Ag} / \mathrm{AgCl}$ (Figure 2a). However, in neutral and alkaline media ( $\mathrm{pH}=7$ and 12), the redox peaks of PoPD are almost non-existent. This has been previously described by the fact that a

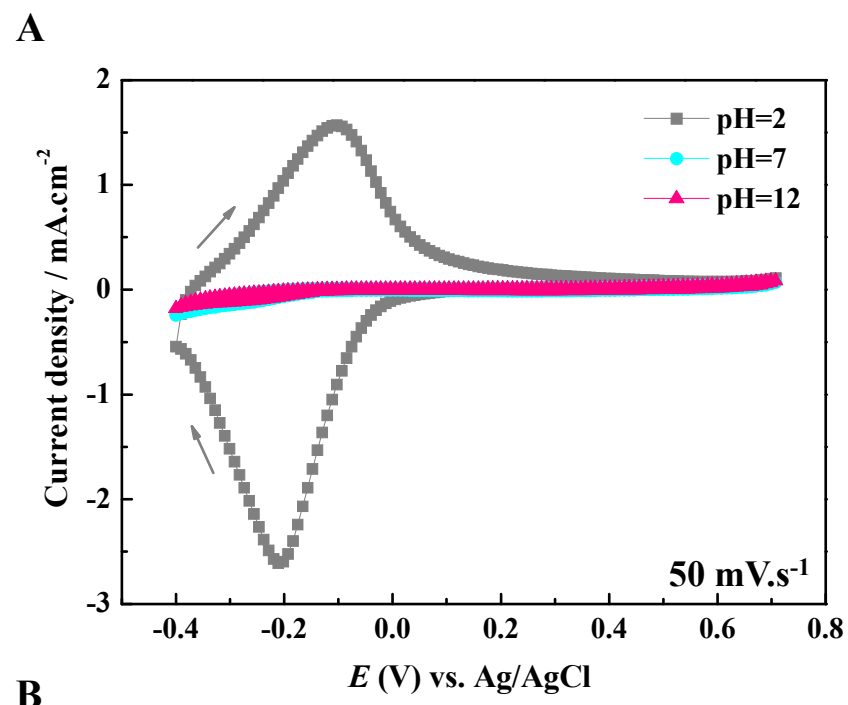

B

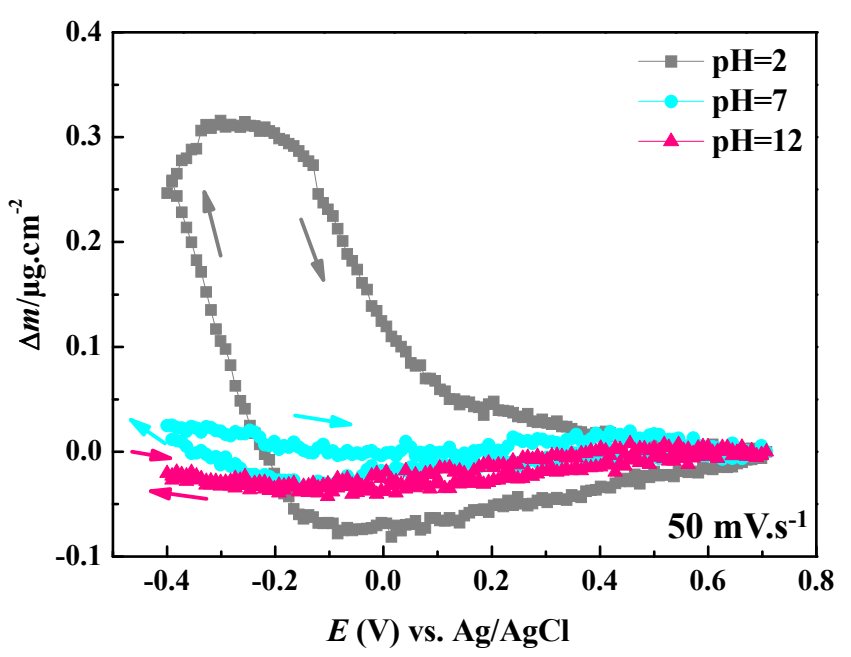

Fig. 2. (a) $\mathrm{CV}$ curves and (b) the corresponding mass variations $(\Delta m)$ of a PoPD film electrodeposited on a gold coated quartz resonator. Measurements are performed in $0.5 \mathrm{M} \mathrm{NaCl}$, at different $\mathrm{pH}(\mathrm{pH}=2,7$ and 12$)$, at a scan rate of $50 \mathrm{mV} \cdot \mathrm{s}^{-1}$. 
proton addition-elimination process participates to the charge compensation, occurring due to the electron transfer, together with the motion of electrolyte ions [46]. The corresponding mass variations were also reported as a function of potential (Figure $\mathbf{2 b}$ ). In acidic media, a significant mass change is observed between $-0.4 \mathrm{~V}$ and $0.2 \mathrm{~V} v \mathrm{sg} / \mathrm{AgCl}$, which can be attributed to (i) the electroadsorption/electrodesorption and/or insertion/deinsertion of the ions and to (ii) the transfer of water molecules. On the contrary, in neutral and alkaline media, the mass responses remain almost unchanged in the explored potential range. This $\mathrm{pH}$ dependant phenomenon has been discussed in the literature considering the fact that (i) intrinsic electron-transfer process between adjacent electroactive sites, (ii) the proton addition-elimination process, (iii) the charge compensation by the counter ion and the solvent transfer are all involved in the charge transfer and transport process of the PoPD film. Among these concurrent processes, the protons additionelimination is considered as a prerequisite for the charge compensation process to proceed [46]. The presented electrogravimetric responses shown in Figure 2 are in good agreement with the above discussion. Based on these results, the acidic media $(\mathrm{pH}=2)$ was chosen for further investigation.

The CV curves in Figure 3a shows a pair of well-defined peaks indicating the electrochemical redox reaction of PoPD, with a peak-to-peak separation of $60 \mathrm{mV}$ at $25 \mathrm{mV} \cdot \mathrm{s}^{-1}$. The value of peak-to-peak separation increases with the increase of the scan rate, which can be explained by a limitation in the process of charge transfer [46]. The scan rate dependence of the electrochemical response is also reflected in the corresponding mass variations. The general appearance of the Figure 3b indicates a mass increase during reduction and mass decrease during oxidation of the PoPD film. With an initial assessment, this can be considered as the characteristic of a major cation response. This behaviour is more dominant at lower scan rates $\left(25 \mathrm{mV} \cdot \mathrm{s}^{-1}\right)$ but becomes more complex especially in the anodic scan of the CVs at higher sweep rates, which can lead to 
A

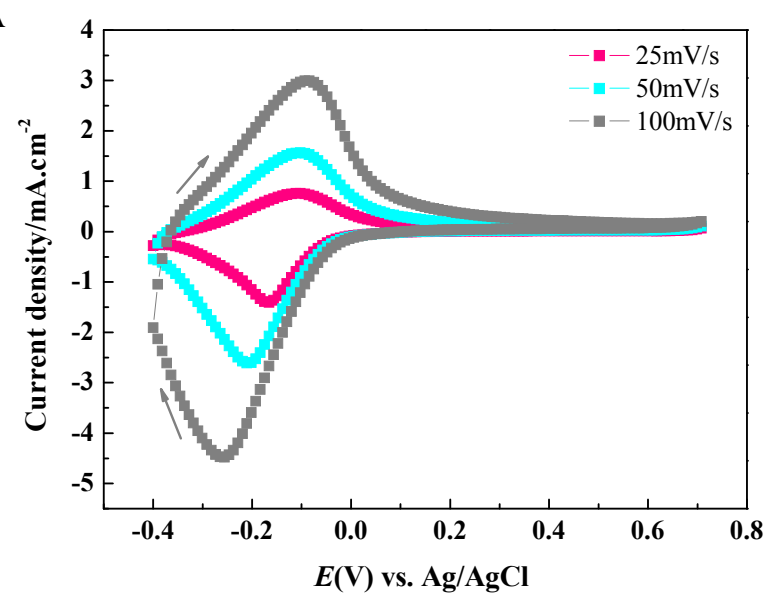

B

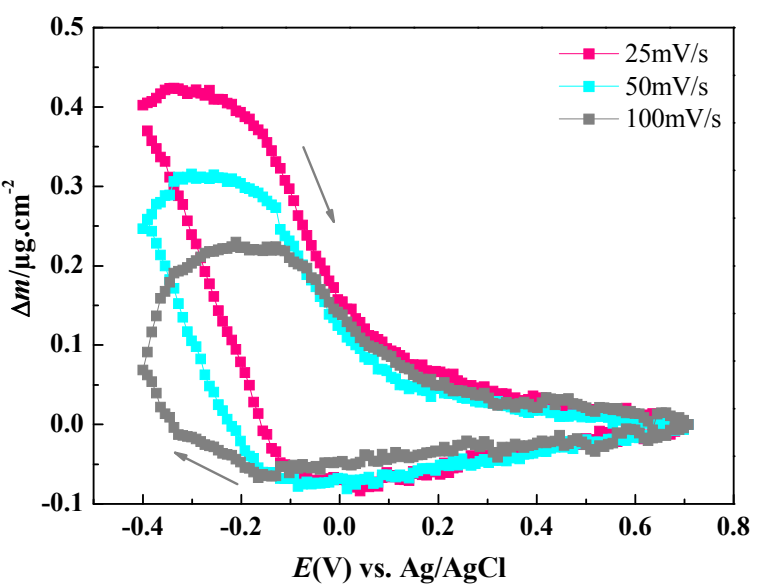

C

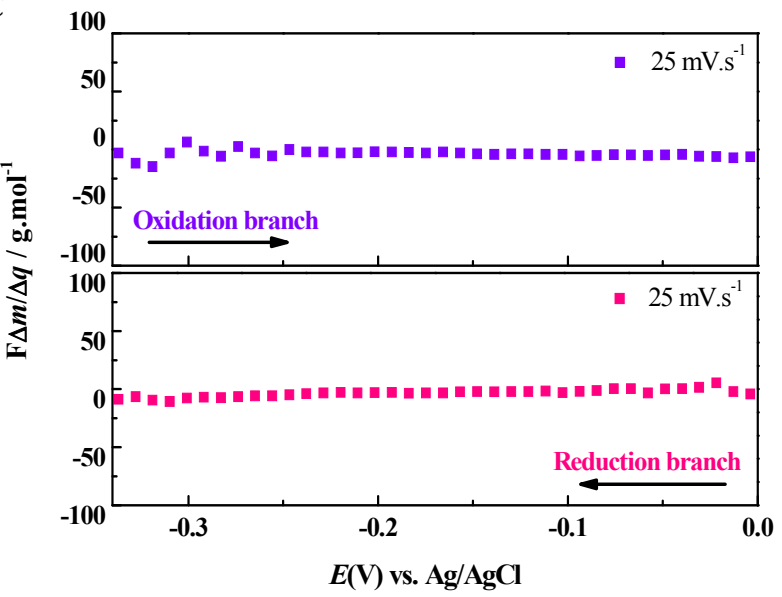

Fig. 3. (a) CV curves, (b) the corresponding mass variation and (c) the $\mathrm{F} \frac{\Delta m}{\Delta q}$ function of PoPD film deposited on the gold coated quartz resonator measured in $0.5 \mathrm{M} \mathrm{NaCl}$, with different scan rates, at $\mathrm{pH}=2$. 
the idea that there is a multi-species transfer phenomena occurring with different proportions and kinetics. In-depth analysis of the EQCM data actually indicates a cation and anion mix contribution to the charge compensation process, which is more evident at higher scan rates by the presence of the slope changes during a certain potential scan direction (Figure 3b). It is noted that anions contribution appears as a mass decrease during reduction and a mass increase during oxidation (for cations, it is vice versa) [31-33]. The scan rate dependant mass response implies the presence of a slower cation(s) contribution which cannot be detected at higher scan rates and this/these cation(s) contribution becomes more dominant at $25 \mathrm{mV} \cdot \mathrm{s}^{-1}$.

The mass per electron $(M P E=F \times(\Delta m / \Delta q))$ calculated from the EQCM data can provide indications of the nature of the transferred species during cycling. If only one species is involved in the charge storage process, the value of MPE would be its molar mass. The cation and anion contributions lead to negative and positive signs of $M P E$ values, respectively [33, 34]. Figure 3c presents the MPE of the species involved during EQCM at $25 \mathrm{mV} \cdot \mathrm{s}^{-1}$ (calculated for oxidation and reduction), presenting a value ranging from -10 to $-5 \mathrm{~g} \cdot \mathrm{mol}^{-1}$, respectively. From these two values and the MPE of $\mathrm{Na}^{+}, \mathrm{Cl}^{-}$and $\mathrm{H}^{+}$of $-23 \mathrm{~g} \cdot \mathrm{mol}^{-1}, 35 \mathrm{~g} \cdot \mathrm{mol}^{-1}$ and $-1 \mathrm{~g} \cdot \mathrm{mol}^{-1}$, respectively, it is more likely that a multi-ion contribution in the charge compensation process is present. Earlier works strengthen this idea by describing that the PoPD films can contain solvent molecules and ionic species at all oxidation states $[19,25]$. Therefore, this deviation between the experimental and theoretical MPE values merits a special analysis. Thus, electrogravimetric impedance spectroscopy (ac-electrogravimetry) was performed to complement the EQCM data and to get a deeper insight into the interfacial charge compensation behavior occurring in the PoPD thin film electrode, from both gravimetric and kinetic point of view.

\subsubsection{Electrogravimetric Impedance Study ( $A c$-electrogravimetry).}



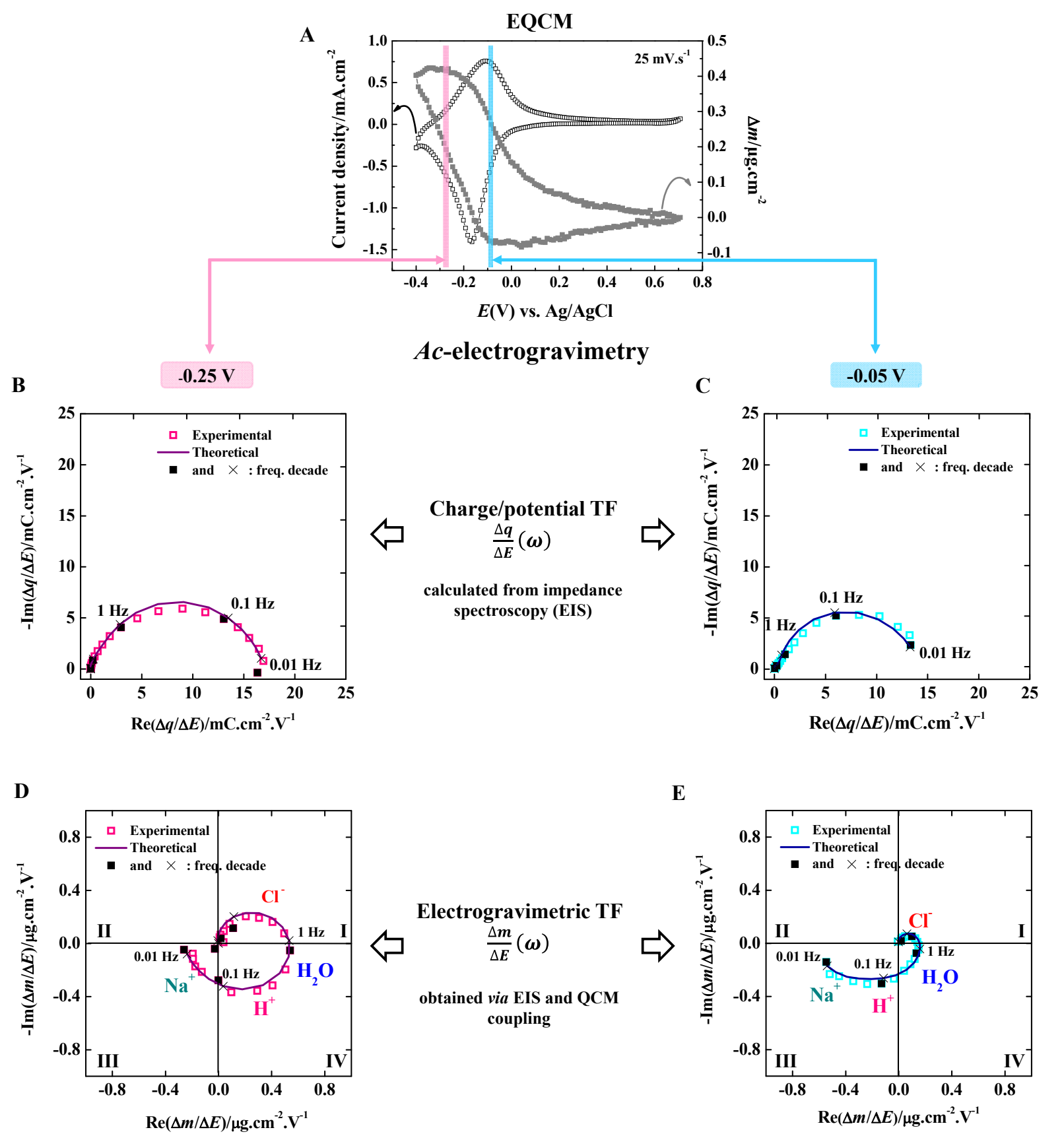

Fig. 4. (a) EQCM curve and (b to e) Ac-electrogravimetry data shown at two selected potentials. The $\frac{\Delta q}{\Delta E}(\omega)$ transfer function at (b) $-0.05 \mathrm{~V}$ and (c) $-0.25 \mathrm{~V}$ (c); and $\frac{\Delta m}{\Delta E}(\omega)$ transfer function at (d) $-0.05 \mathrm{~V}$ (d) and (e) $-0.25 \mathrm{~V}$ of the PoPD film measured in $0.5 \mathrm{M} \mathrm{NaCl}$ solution at $\mathrm{pH}=2$. The fitting parameters are given in Table SI-1. 
(i) Identification of the species contributing to the charge compensation: Ac-electrogravimetric measurements were carried out at various states-of-polarization from $-0.05 \mathrm{~V}$ to $-0.25 \mathrm{~V} v \mathrm{~s}$ $\mathrm{Ag} / \mathrm{AgCl}$ with an interval of $50 \mathrm{mV}$, these potential range corresponds to the highest slope of the mass-potential curve in the EQCM data shown in Figure 4a. Two important transfer functions $(\mathrm{TF})$, charge/potential TF $(\Delta q / \Delta E(\omega))$ (derived from impedance, $\Delta E / \Delta I(\omega))$ and mass/potential TF $(\Delta m / \Delta E(\omega))$ are obtained from ac-electrogravimetry, as described earlier [31-34]. Distinct from $\Delta q / \Delta E(\omega)$ which considers only the interfacial transfer of ionic species, the $\Delta m / \Delta E(\omega)$ estimates the species nature and also takes the free solvent contribution into account $[31,32]$. The electrochemical impedance, $\Delta E / \Delta I(\omega)$ and charge/potential TF, $\Delta q / \Delta E(\omega)$ (Figure SI-1 and SI-2, Figure $4 \mathbf{b}$ and $4 \mathbf{c}$ ) at selective potentials of -0.25 and $-0.05 \mathrm{~V}$ vs $\mathrm{Ag} / \mathrm{AgCl}$ are firstly compared. They reveal the contribution of charged species participating in the charge compensation process. The electrochemical impedance, (Figure SI-1 and SI-2) at low frequencies exhibits a slightly distorted straight line implying a multi-ion contribution to the charge compensation process which is reflected as depressed semi-circles in the charge/potential TFs (Figure 4b and 4c). However, the time constants of participating species are not different enough to be seen as separate loops. Then, the experimental data of impedance and charge/potential TF (Figure SI-1 and SI-2, Figure 4b and 4c) were fitted using theoretical functions given in Equations 1 and 2:

$$
\begin{aligned}
& \frac{\Delta E}{\Delta I}(\omega)=\left(j \omega d_{f} F \sum_{i} \frac{G_{i}}{j \omega d_{f}+K_{i}}\right)^{-1} \quad \text { (i: ions) } \\
& \frac{\Delta q}{\Delta E}(\omega)=F d_{f} \sum_{i} \frac{G_{i}}{j \omega d_{f}+K_{i}} \quad \text { (i: ions) }
\end{aligned}
$$


where $K_{i}$ represents the kinetics, $G_{i}$ describes the ease or difficulty of each species' transfer at the electrode/electrolyte interface, $d_{f}$ relates the film thickness and $F$ is Faradays' constant. This fitting process revealed the involvement of three different ionic species which resulted in a good agreement between the experimental and the theoretical curves (Figure $\mathbf{4 b}$ and $\mathbf{4 c}$, Figure SI-1 and SI-2). The fitting parameters are presented in Table SI-1. The classical impedance and the charge/potential TF provide the investigation of the charged species' contribution but do not permit their identification. Thus, $\Delta m / \Delta E(\omega)$ TFs were explored for tracking the flux of both charged and neutral species and to achieve their identification and the estimation of their kinetics related to the interfacial transfer.

Figure 4d and 4e present the experimental and theoretical $\Delta m / \Delta E(\omega)$ TFs which show several well defined semi-circles appearing at different quadrants. It is important to note that the contributions in the first/fourth and the second/third quadrant are due to the anion and cation transfer, respectively (details of the methodology can be found in Refs.[31, 32, 34]). Free solvent molecules can appear in the same quadrant either with anions or with cations, depending on their flux direction, i.e., the same flux direction with anions or cations [34].

For the fitting process of the $\Delta m / \Delta E(\omega) \mathrm{TF}$, two parameters $\left(K_{i}\right.$ and $\left.G_{i}\right)$ previously obtained from impedance and charge/potential TF for each ionic species (Figure $\mathbf{4 b}$ and $\mathbf{4 c}$ ) are used in

\section{Equation 3:}

$\frac{\Delta m}{\Delta E}(\omega)=-d_{f} \sum_{i} M_{i} \frac{G_{i}}{j \omega d_{f}+K_{i}}$ (i: ions and neutral species)

(Equation 3)

Notably, the identification of the participants in charge compensation process can be achieved thanks to the molar mass $\left(M_{i}\right)$ of the species intervening in electrogravimetric TF $(\Delta m / \Delta E(\omega))$ 
(Equation 3). The fitting of the experimental $\Delta m / \Delta E(\omega)$ data (measured in $0.5 \mathrm{M} \mathrm{NaCl}$ and at $\mathrm{pH}=2$ ) using theoretical function in Equation 3 revealed a configuration involving the transfer of anions $\left(\mathrm{Cl}^{-}\right)$, cations $\left(\mathrm{H}^{+}\right.$and $\left.\mathrm{Na}^{+}\right)$and free $\mathrm{H}_{2} \mathrm{O}$ molecules which leads to a good agreement

A

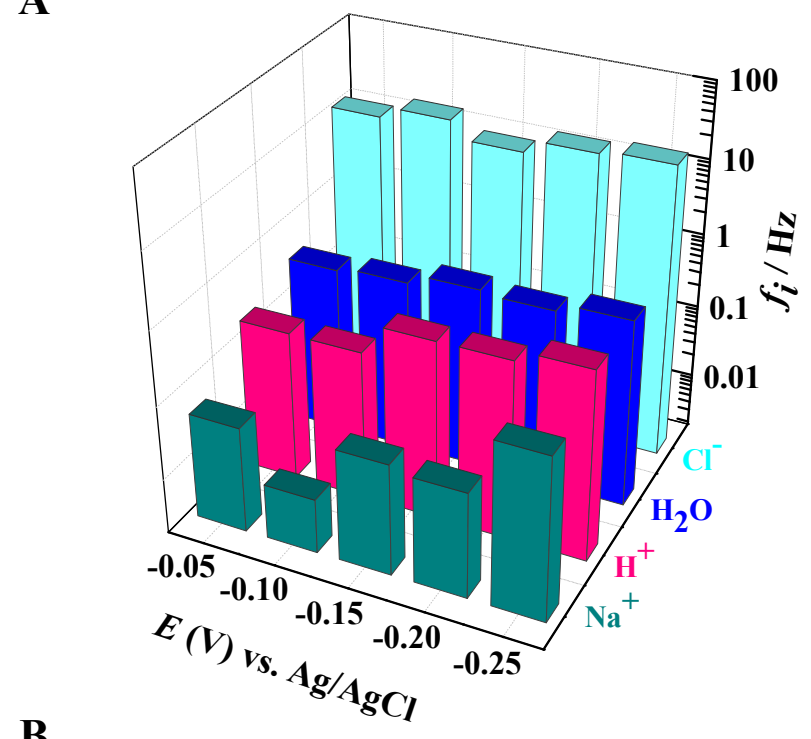

B

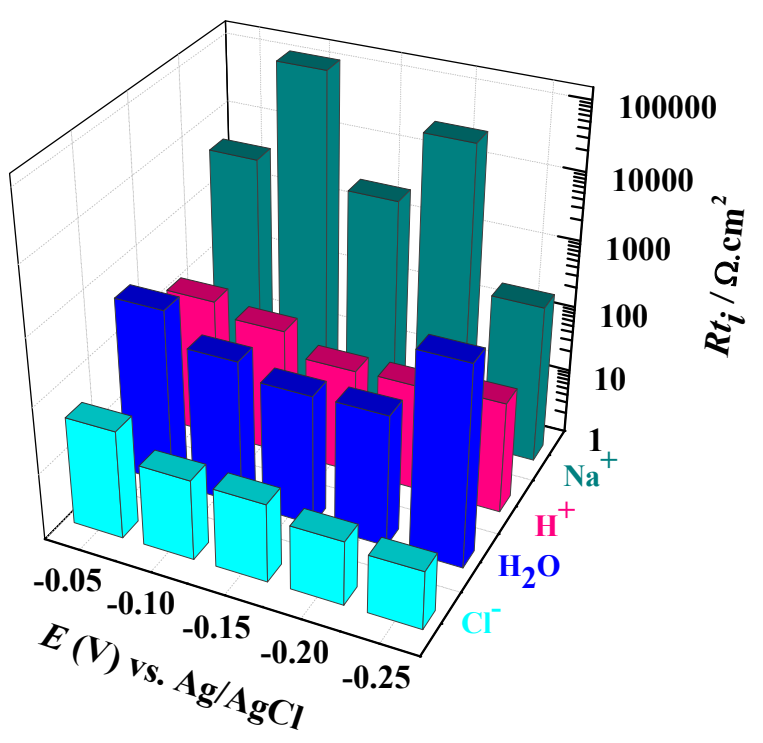

Fig. 5. Variation of the (a) transfer resistance $\left(R t_{i}\right)$ and (b) characteristic frequency $\left(f_{i}\right)$ for PoPD film deposited on the gold coated quartz resonator, measured in $0.5 \mathrm{M} \mathrm{NaCl}$ at $\mathrm{pH}=2$. The $f_{i}$ and $R t_{i}$ values are given in Table SI-1. 
between experimental and theoretical data (Figure 4d and 4e).

(ii) Dynamics of interfacial transfer of species: Since these measurements are frequency dependent, it is also possible to get information on the kinetics of interfacial ion transfer. At both potentials shown in Figures $\mathbf{4 d}$ and $\mathbf{4 e}, \mathrm{Cl}^{-}$anions were identified at high frequencies (HFs) indicating a faster process, followed by the transfer of water molecules with an opposite flux direction. Lastly, $\mathrm{H}^{+}$and $\mathrm{Na}^{+}$cations were exchanged at lower frequencies (LFs), exhibiting also opposite flux direction to anions.

The other potentials studied in the range of " $0.05 \mathrm{~V}$ to $-0.25 \mathrm{~V} v s \mathrm{Ag} / \mathrm{AgCl}$ " indicate the persistence of multi-species contribution, with slight variations in quantity and in terms of kinetics of transfer. Form their $K_{i}$ and $G_{i}$ parameters, the characteristic frequency, $f_{i}$, and the resistance of transfer, $R t_{i}$, can be calculated using the $f_{i}=\frac{K_{i}}{\pi d_{f}}$ and $R t_{i}=\frac{1}{\mathrm{FG}}$ relations, respectively (Figure 5a and 5b). In the potential range studied, the tendency of $f_{i}\left(\mathrm{Cl}^{-}\right)>f_{i}\left(\mathrm{H}_{2} \mathrm{O}\right)$ $>f_{i}\left(\mathrm{H}^{+}\right)>f_{i}\left(\mathrm{Na}^{+}\right)$is observed (Figure 5a) presenting the order of the kinetics of transfer of the species which is inversely proportional to their resistance of transfer, $R t_{i}$, at most of the potentials shown in Figure 5b.

The multi species contribution with different interfacial transfer kinetics revealed in $a c$ electrogravimetry is in good agreement and also strengthens the ideas discussed previously to explain the scan rate dependent mass-potential curves in EQCM (Figure 3a and 3b). In a simplistic discussion, the redox behavior of PoPD thin film can be compensated either by insertion of anions or expulsion of cations during oxidation (vice versa during reduction). In the EQCM data in Figure 3b, during oxidation at high scan rates $\left(100 \mathrm{mV} \cdot \mathrm{s}^{-1}\right)$, a mass increase is followed by a subsequent mass diminution. This observation may correspond to the insertion of anions which is followed by the expulsion of cations and/or water molecules by exclusion. Since 
$a c$-electrogravimetry results indicate the opposite flux direction of solvent molecules which appear at the following frequencies right after the anions (Figure $\mathbf{4 d}$ and $\mathbf{4 e}$ ), it is more likely that anions insertion during oxidation excludes some water molecules which results in this subsequent mass decrease during oxidation (Figure 3b). However, this cannot be the only contribution, since in the reverse scan during reduction, a mass increase is observed. The water molecules alone cannot explain the specific shape of the gravimetric response during the reduction process. Thus,
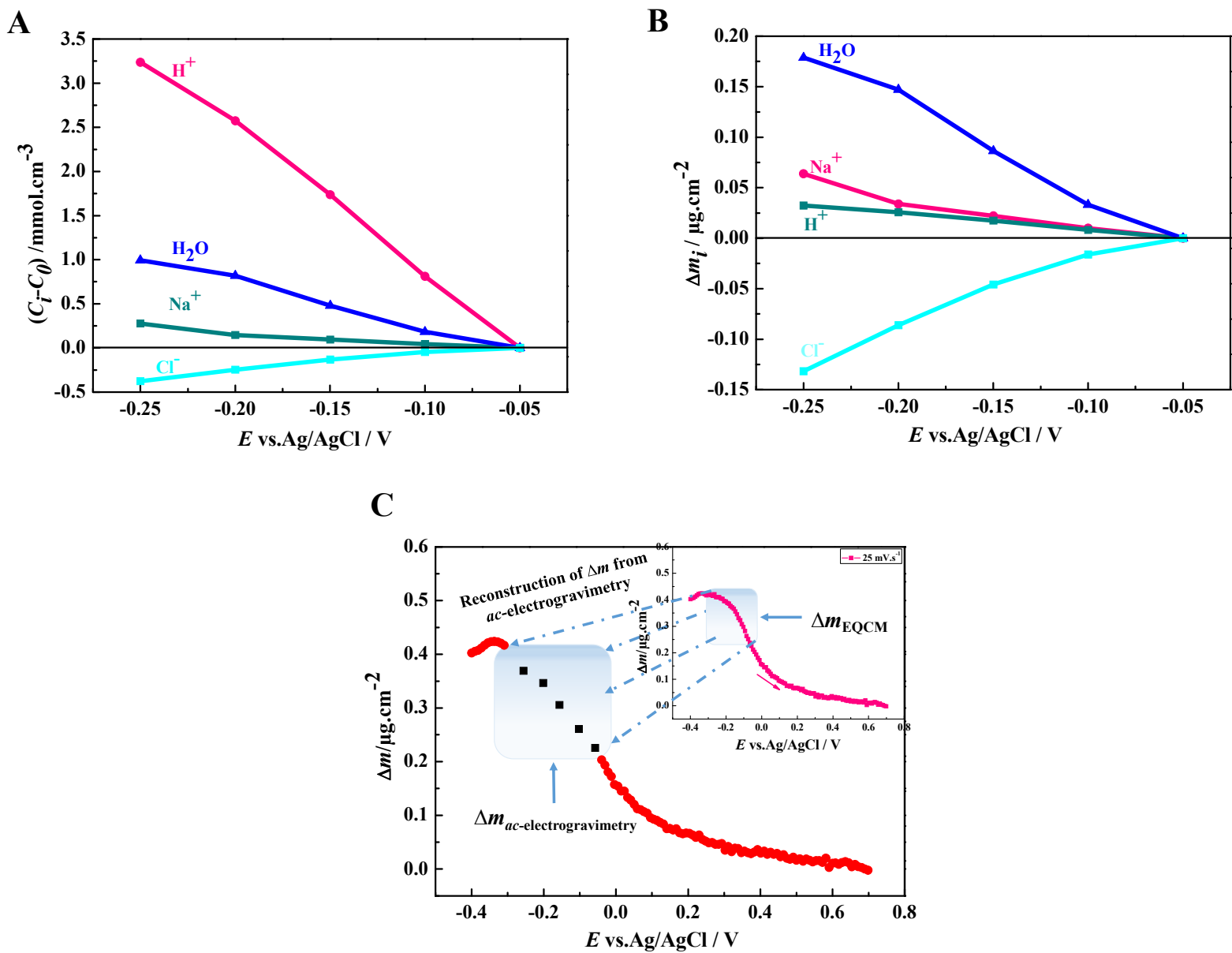

Fig. 6. The ac-electrogravimetric results of the PoPD film deposited on the gold coated quartz resonator. (a) The variation of the relative concentration $\left(\mathrm{Ci}-\mathrm{C}_{0}\right)$, (b) the relative mass variation of each species measured in $\mathrm{NaCl} 0.5 \mathrm{M}, \mathrm{pH}=2$ and (c) the reconstruction of total mass variation from ac-electrogravimetric results and comparison with the EQCM response at $25 \mathrm{mV} \cdot \mathrm{s}^{-1}$. 
there should be a contribution from the cationic species in the electrogravimetric response, as well. This behavior observed at $100 \mathrm{mV} \cdot \mathrm{s}^{-1}$ becomes less and less obvious at lower scan rates (i.e. 25 and $50 \mathrm{mV} \cdot \mathrm{s}^{-1}$ ) and the EQCM curves becomes dominant in a typical cationic response (Figure 3b). This is explained by the $a c$-electrogravimetry results showing the contribution of the $\mathrm{H}^{+}$and $\mathrm{Na}^{+}$at lower frequencies. Consequently, the contribution of cations is hardly detected at high scan rates, but starts to dominate the electrogravimetric response at lower scan rates. These results are in good agreement with the discussion of Inzelt et al. on the PoPD charge compensation behavior and provide experimental data for the disentangling the redox behavior of PoPD thin films [25].

(iii) Complementarity of ac-electrogravimetric and EQCM results - Gravimetric contribution of each species: To further shed light on the multi-species contribution to the charge storage and their interfacial transfer, an approach benefiting from the complementarity of the EQCM and $a c$ electrogravimetry is proposed. Specifically, the relative concentration changes of each species $\left(\Delta C_{i}\right)$ with respect to the potential variation $(\Delta E)$ can be obtained from ac-electrogravimetry by using Equation 4, which lead to the estimation of the relative concentration changes of each species between the different states-of-polarization through an integration process as shown in Equation 5:

$$
\begin{aligned}
& \frac{\Delta C_{i}}{\Delta E}(\omega)=\frac{-G_{i}}{j \omega d_{f}+K_{i}} \\
& C_{i}-C_{0}=\left.\int_{E_{0}}^{E_{i}} \frac{\Delta C_{i}}{\Delta E}(\omega) d E\right|_{\omega \rightarrow 0}=\int_{E_{0}}^{E_{i}} \frac{-G_{i}}{K_{i}} d E
\end{aligned}
$$

The relative concentration changes $\left(\boldsymbol{C}_{\boldsymbol{i}}-\boldsymbol{C}_{\mathbf{0}}\right)$ of individual species identified from acelectrogravimetry are presented in Figure 6a. It is important to note that the relative concentration variation of $\mathrm{H}^{+}$is the highest among the other charged or non-charged species 
which is in agreement with the $\mathrm{pH}$ dependent EQCM results given in Figure 2b. However, when Figure 6a is transformed into corresponding mass variations (Figure 6b), gravimetric contributions present a different behavior, anions and water molecules start dominating the $\Delta m$ response. Furthermore, the gravimetric reconstruction can be obtained by the addition of individual mass contributions from all species concerned in $a c$-electrogravimetry (Figure $\mathbf{6 c}$, shown in the range of "0.05 V to $-0.25 \mathrm{~V} v s \mathrm{Ag} / \mathrm{AgCl}$ "). A good agreement between $\Delta m$ (global) measured with the classical EQCM (at $25 \mathrm{mV} \cdot \mathrm{s}^{-1}$ ) and reconstructed $\Delta m$ from $a c$ electrogravimetry is achieved (Figure 6c) in the studied potential range. This comparison provides a support for the multi-species' contribution revealed by ac-electrogravimetry and further evidences the complementarity of the EQCM and ac-electrogravimetry.

It can be emphasized that charge compensation process of PoPD in aqueous electrolytes (in acidified $\mathrm{NaCl}$ ) occurs with the participation of multiple species, each playing a role at different temporal scales. Although gravimetrically not significant, the contribution of $\mathrm{H}^{+}$to the charge storage mechanism is highlighted, i.e. (i) more than ten times of $\mathrm{Na}^{+}$ion's concentration variation in the electrode during cycling (Figure 6a) and (ii) their interfacial transfer is faster than that of $\mathrm{Na}^{+}$(Figure 6b) under the conditions of our study.

\subsection{Pseudo-capacitive charge storage performances.}

\subsubsection{Thin film PoPD electrodes-half cell performance (3-electrode configuration).}

The charge storage performances were measured in $\mathrm{NaCl} 0.5 \mathrm{M}$ at $\mathrm{pH}=2$. The specific capacitance can be calculated from the CV curves using the following relation, $C_{s}=\frac{1}{2 m v\left(E_{2}-E_{1}\right)} \int_{E_{1}}^{E_{2}} I(E) d E$, where $m$ is the mass loading of PoPD electrodes obtained 

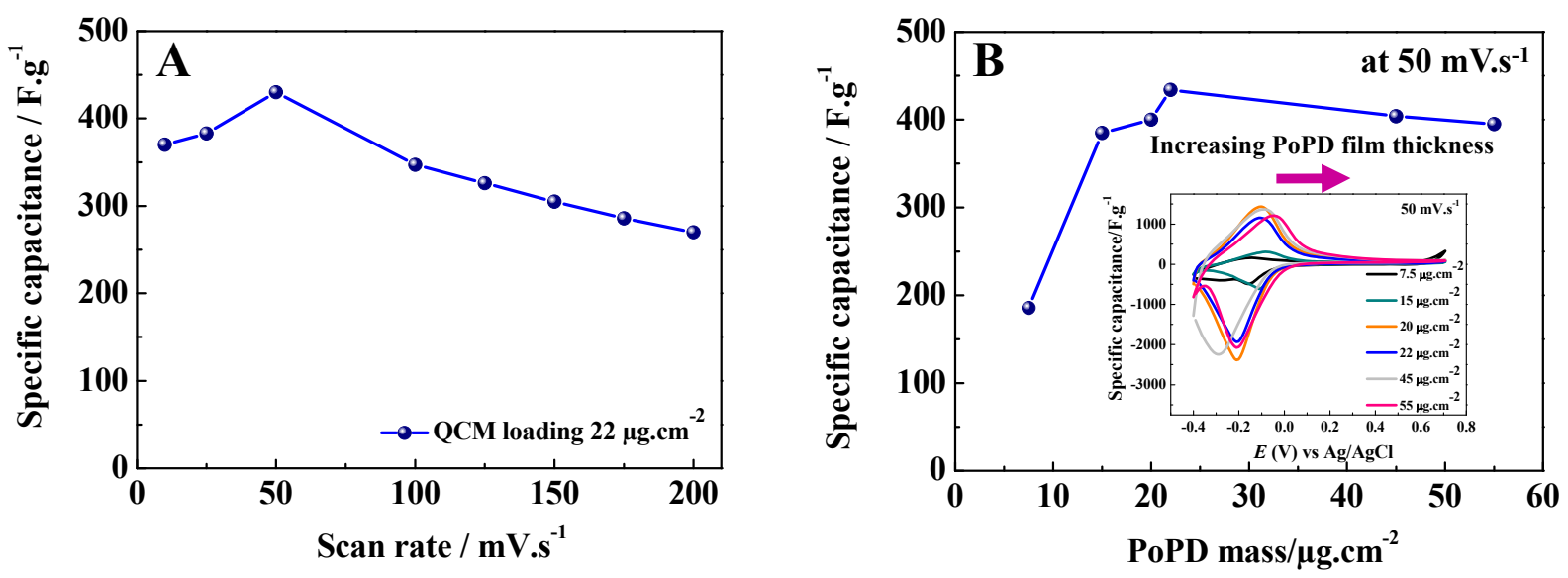

Fig. 7. Variation of the specific capacitance $\left(C_{s}\right)$ of PoPD films deposited on gold-coated QCM and measured in $\mathrm{NaCl} 0.5 \mathrm{M}, \mathrm{pH}=2$. $C_{s}$ is plotted (a) as a function of the potential scan rate (loading of $22 \mu \mathrm{g} \cdot \mathrm{cm}^{-2}$ ) and (b) as a function of the loading of the QCM resonator at $50 \mathrm{mV} \cdot \mathrm{s}^{-1}$. Apparent gold electrode surface on the QCM is $0.2 \mathrm{~cm}^{2}$.

by QCM, $v$ is the scan rate, $E_{1}$ and $E_{2}$ are the low and high end potentials, and $I(E)$ depicts the response in current. The PoPD thin film electrodes used in the previous sections were about 4.4 $\mu \mathrm{g}$ for $0.2 \mathrm{~cm}^{2}$ of the gold electrode of the quartz resonators $\left(22 \mu \mathrm{g} \cdot \mathrm{cm}^{-2}\right)$. The loading of the resonators was determined by measuring the frequency changes before and after the film formation.

First of all, the $C_{s}$ values as a function of the scan rate used in the $\mathrm{CV}$ analysis are presented in Figure 7a. For this analysis, the typical loading of $\sim 22 \mu \mathrm{g} \cdot \mathrm{cm}^{-2}$ was used, which corresponds to a film thickness of $\sim 150 \mathrm{~nm}$ estimated through FEG-SEM analysis (Figure 1d).

The $C_{s}$ values were decreased with an increase in the scan rate from a maximum value of 430 $\mathrm{F} \cdot \mathrm{g}^{-1}$ at $50 \mathrm{mV} \cdot \mathrm{s}^{-1}$ to $270 \mathrm{~F} \cdot \mathrm{g}^{-1}$ at $200 \mathrm{mV} \cdot \mathrm{s}^{-1}$ (Figure 7a). However, the $C_{s}$ values at the scan rates of 10 and $25 \mathrm{mV} \cdot \mathrm{s}^{-1}$ are slightly lower than that of $50 \mathrm{mV} \cdot \mathrm{s}^{-1}$ and deviates from the usual scan rate dependency trend of the $C_{s}$ (Figure 7a). This behavior has previously been observed for 
thin conducting polymer or metal/metal oxide based electrodes in aqueous electrolytes $[48,49]$ and deserves to be further investigated.

Additionally, the $C_{s}$ values obtained in our study, are in the same order of magnitude or even higher than some of the earlier reports on CPs (Table SI-2) [11, 50-53]. However, it is important to recognize that the $C_{s}$ values depends on various factors, such as the synthesis route, additives, dopants, morphology, porosity, as well as the measurement configuration [7, 21].

Then, in order to check the effect of the film thickness, several films were prepared by increasing the number of $\mathrm{CV}$ cycles during their electrodeposition. The specific capacitance $\left(C_{s}\right)$ of the PoPD thin films is evaluated as a function of the loading (proportional to film thickness) at a scan rate of $50 \mathrm{mV} \cdot \mathrm{s}^{-1}$. As shown in Figure $7 \mathbf{b}, C_{s}$ values presents two different trends as a function of the loading (i.e. in the range of $7.5-22 \mu \mathrm{g} \cdot \mathrm{cm}^{-2}$ and $22 \mu \mathrm{g} \cdot \mathrm{cm}^{-2}-55 \mu \mathrm{g} \cdot \mathrm{cm}^{-2}$ ). It starts with a markedly different behaviour of the $7.5 \mu \mathrm{g} \cdot \mathrm{cm}^{-2}$ loading (electrodeposited by $50 \mathrm{CV}$ cycles), which shows the lowest $C_{s}$ value. Probably $50 \mathrm{CV}$ cycles are not enough to form the PoPD structure completely (and the electrode surface is not fully covered (Figure SI-3)), which is in agreement with the absence of well-defined redox peaks in the CV response shown in Figure $7 \mathbf{b}$ inset. Following this value, $C_{s}$ shows a significant increase in the range of $7.5-22 \mu \mathrm{g} \cdot \mathrm{cm}^{-2}$, reaching to values as high as $\sim 434 \mathrm{~F} \cdot \mathrm{g}^{-1}$ at $22 \mu \mathrm{g} \cdot \mathrm{cm}^{-2}$.

However, when the loading (thickness) of the film is further increased (i.e. to $\sim 55 \mu \mathrm{g} \cdot \mathrm{cm}^{-2}$ ) a slight capacitance fading is noticed in the range of $22 \mu \mathrm{g} \cdot \mathrm{cm}^{-2}-55 \mu \mathrm{g} \cdot \mathrm{cm}^{-2}$ (Figure 7b). This behaviour can be related to the mass transport limitation of the ions resulting in higher overpotentials upon cycling within a fix voltage range [54]. 
Note that higher loadings are not investigated on the quartz resonators to be able to maintain the gravimetric regime for the analysis [25], for that reason thicker electrodes are tested in a two electrode Swagelok configuration on graphite electrodes.

\subsubsection{Thicker film PoPD electrodes-full cell performance (2-electrode configuration).}

Figure 8 presents the galvanostatic charge-discharge (GCD) performance of the PoPD electrode deposited on a graphite electrode. The mass loading and the thickness of the electrode is around $100 \mu \mathrm{g} \cdot \mathrm{cm}^{-2}$ and $700 \mathrm{~nm}$, respectively. The mass loading is two times higher than that of the maximum mass deposited on $\mathrm{Au}$ coated quartz electrodes (Figure 7b). The current applied to the electrode is $0.63 \mathrm{~mA} \cdot \mathrm{cm}^{-2}\left(6.3 \mathrm{~A} \cdot \mathrm{g}^{-1}\right)$ that is equivalent to $30 \mathrm{C}$ current density. The test was performed in 2 electrode cell in which $\mathrm{Zn}$ is used as both reference and counter electrodes. A characteristic pseudo-capacitive behaviour is observed in which voltage-time graph has not a triangular shape (Figure 8a and 8b), but instead, obvious oxidation and reduction peaks appear at around 0.85 and $0.5 \mathrm{~V}$ vs Zn, respectively, as depicted in the inlet figure of Figure 8c. Indeed, those well-defined peak positions are in a well agreement with the 3-electrode measurements performed with a $\mathrm{Ag} / \mathrm{AgCl}$ reference electrode (Figure 3a) since the reference electrode potentials of $\mathrm{Ag} / \mathrm{AgCl}$ ( $v s \mathrm{SHE}$ ) is $+0.197 \mathrm{~V}$ and $\mathrm{Zn}$ is -0.760 (vs SHE). The electrode exhibited excellent cycling performances with a stable capacitance (around $110 \mathrm{~F} \cdot \mathrm{g}^{-1}$ ) and columbic efficiency close to $100 \%$ without negligible capacitance fade over 8000 cycles at $0.63 \mathrm{~mA} \cdot \mathrm{cm}^{-2}$ current density. The gravimetric capacitance value $\left(110 \mathrm{~F} \cdot \mathrm{g}^{-1}\right)$ corresponds to an areal capacitance of $11 \mathrm{mF} \cdot \mathrm{cm}^{2}$ since we have a loading of $\sim 100 \mu \mathrm{g} / \mathrm{cm}^{-2}$. These values are relatively small compared with the $C_{s}$ values obtained for the thin film PoPD electrodes in the three electrode configuration at $50 \mathrm{mV} \cdot \mathrm{s}^{-1}$ (Figure 7). This could be attributed to the increased distance of electron transport from the thicker PoPD electrode to the current collector which is in 
agreement with the thickness dependence of the specific capacitance as shown in metal oxide or conducting polymer electrodes $[55,56]$. Furthermore, the post mortem FEG-SEM images of the PoPD on graphite and Zn electrode are provided in supporting information (Figure SI-4 and 5, respectively) and compared with those of the fresh electrodes. No significant morphological changes were observed even after 8000 cycles (under the conditions of our study), except the presence of residual glass fibers originating from the separator used in the Swagelok tests (identified by the EDX analysis shown in Figure SI-4, panel E). It is noted that detachment of the glass fibers is not significant enough to affect the structural integrity of the separator, thus it is not detrimental to the cell performance, at least for 8000 cycles.

In order to better position the performance of the PoPD based electrodes, they are compared with the limited number of studies exist which report on the capacitive behaviour of pristine PoPD $[18,21]$ and PoPD composites [57-59]. Wang et al. described the electrochemical synthesis of PoPD in the presence of sodium dodecyl sulphate (SDS) surfactant [18]. The resulting materials were tested by charging/discharging in $1 \mathrm{M} \mathrm{KNO}_{3}$ at the current density of $0.5 \mathrm{~A} \cdot \mathrm{g}^{-1}$ in the potential range of -0.2 to $0.6 \mathrm{~V}$ vs $\mathrm{SCE}$ (saturated calomel electrode) in a 3-electrode configuration. A capacitance value of about $106 \mathrm{~F} \cdot \mathrm{g}^{-1}$ were obtained and the electrode retained $82 \%$ of its initial capacitance at the $1000^{\text {th }}$ cycle [18]. Comparing our findings with the results of Wang et al. [18], it is important to note that pseudo-capacitive behaviour of the PoPD is clearly observed under the conditions of our study, as evidenced by the presence of the obvious redox peaks of PoPD (Figure $7 \mathbf{b}$ and $8 \mathbf{c}$ inset). Similar capacitance value (around $110 \mathrm{~F} \cdot \mathrm{g}^{-1}$ ) to that reported in Ref. [18] is obtained, but at a higher current density $\left(6.3 \mathrm{~A} \cdot \mathrm{g}^{-1}\right)$ accompanied with high coulombic efficiency for 8000 cycles, indicating the high rate capability and the excellent cycling stability of the PoPD electrodes of our study (Figure 8c). Furthermore, a more recent 

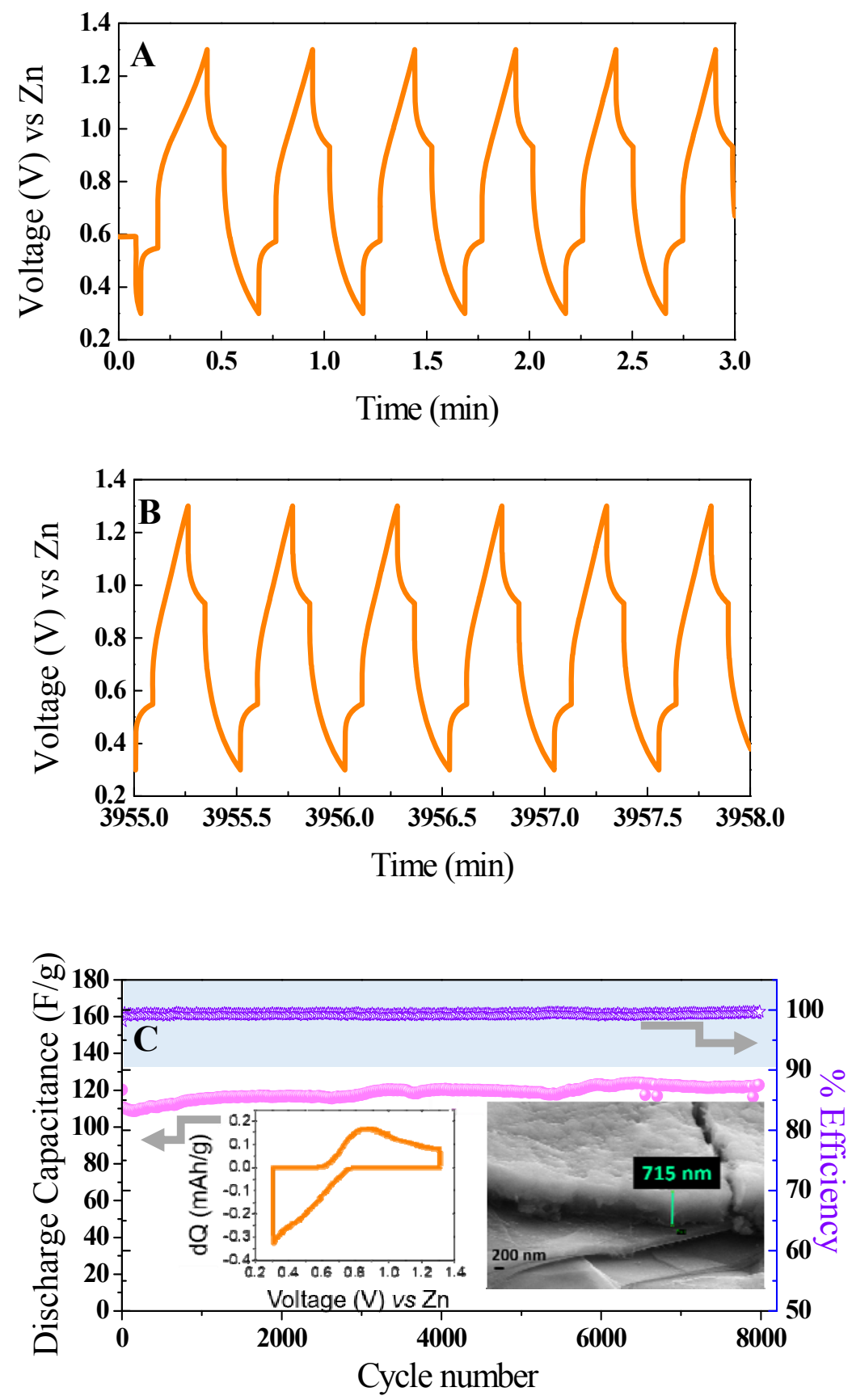

Fig. 8. Galvanostatic charge/discharge curves of PoPD supercapacitor at $30 \mathrm{C}$ current density. (a) and (b) are the voltage-time graphs at different time scale showing electrode's long term stability. (c) discharge capacities as a function of cycle number for the cell. Inset figures: a graph belongs to the first cycle dQ vs V curve and cross section FEG-SEM image of the PoPD coated on graphite electrode. 
study evaluated the capacitive properties of the PoPD electrodes and compared them with the PoPD-PANI copolymer in $1 \mathrm{M} \mathrm{H}_{2} \mathrm{SO}_{4}$ using a 3 electrode configuration. In this case, bare PoPD presented the lowest $C_{s}\left(8.3 \mathrm{~F} \cdot \mathrm{g}^{-1}\right)$, PANI showed a $C_{s}$ of $123 \mathrm{~F} \cdot \mathrm{g}^{-1}$ and PoPD-PANI copolymer exhibited the highest $C_{s}\left(138.9 \mathrm{~F} \cdot \mathrm{g}^{-1}\right)$ at $0.1 \mathrm{~A} \cdot \mathrm{g}^{-1}[21]$. The low value obtained for the pristine PoPD electrode can be attributed to the fact that GCD measurements were conducted in the potential range of $0 \mathrm{~V}$ to $0.6 \mathrm{~V}$ vs $\mathrm{Ag} / \mathrm{AgCl}$, thus only benefiting from the double layer capacitance of the PoPD polymer, but not from its faradaic capacitance which was enhanced in a subsequent step by copolymerization of PoPD with polyaniline [21]. In our study it is highlighted that, the potential range can be optimized to test both capacitive and pseudo-capacitive phenomena of PoPD (Figure 8). As it is widely accepted, the cycling performance is one of the bottleneck in the field of conductive polymer based electrodes $[5,7,18,60]$, and has been tackled with, for example by the encapsulation of the CPs under a protective shell [11]. Therefore, the performances obtained in our study with the pristine PoPD polymer electrodes are quite significant, especially taking into account its very long cycling stability (Figure 8).

\section{CONCLUSIONS}

A thorough electrogravimetric study which employed EQCM and its complementary counterpart electrogravimetric impedance revealed that the charge compensation process of PoPD thin film electrodes in acidified $\mathrm{NaCl}$ electrolyte occurs with the participation of multiple species. This combined methodology identified that the $\mathrm{Cl}^{-}$anions contribute at high frequencies (HFs) indicating a faster process, followed by the transfer of water molecules with an opposite flux direction (excluded by the anions). Lastly, $\mathrm{H}^{+}$and $\mathrm{Na}^{+}$cations were exchanged at lower frequencies (LFs), exhibiting also opposite flux direction to anions. 
Then, the pseudo-capacitive charge storage performances of the thin film electrodes were studied where the PoPD is electrodeposited on the gold-coated quartz resonators. The gravimetric capacitance values $\left(C_{s}\right.$ in $\left.\mathrm{F} \cdot \mathrm{g}^{-1}\right)$ of the thin film electrodes could be obtained thanks to the exact determination of the electrode loadings by QCM. $C_{s}$ values as high as $\sim 434 \mathrm{~F} \cdot \mathrm{g}^{-1}$ are obtained (in a half cell configuration) at a loading of $22 \mu \mathrm{g} \cdot \mathrm{cm}^{-2}$ which is followed by a slight decrease ( $\left.400 \mathrm{~F} \cdot \mathrm{g}^{-1}\right)$ at the loading range of $22-55 \mu \mathrm{g} \cdot \mathrm{cm}^{-2}$. These significantly high $C_{s}$ values may imply an efficient interfacial charge transfer which may occur in the thicker electrode configuration. Accordingly, the pseudo-capacitive charge storage performance of a thicker electrode (in a full cell configuration in which $\mathrm{Zn}$ is used as both reference and counter electrode) presented relatively high $C_{s}$ values $\left(\sim 110 \mathrm{~F} \cdot \mathrm{g}^{-1}\right)$ and a remarkable cycling stability $(\sim 8000$ cycles $)$ with high coulombic efficiency $(\sim 100 \%)$. Although gravimetrically not significant, the contribution of protons to the charge storage mechanism is highlighted since they are detected as the dominant species in terms of concentration variation in the electrode during cycling. Therefore, high rate capability, the excellent cycling stability of the PoPD electrodes accompanied with high coulombic efficiency for 8000 cycles have been correlated to the electrolyte composition and the significant role of $\mathrm{H}^{+}$to the charge compensation process has been unraveled, which was made possible with coupled electrogravimetric methods of our study. Furthermore, our results are distinguished from the limited number of reports on the charge storage performance of PoPD based electrodes, where in the present study, the experimental conditions were optimized to have the contributions from both the double layer and the faradaic capacitance. The fact that the pristine thin film PoPD polymer electrode has significant cycling stability shows its promise as an electrode or electrode component in micro energy storage devices. 


\section{ACKNOWLEDGEMENTS}

This work was sponsored by MESRSFC (Ministère de l'Enseignment Supérieur et de la Recherche Scientifique et de la Formation des Cadres of Morocco) and CNRST (Centre National pour la Recherche Scientifique et Technique) (Project number PPR/2015/72). The authors thank Mrs. Stéphanie Delbrel and Mrs. Françoise Pillier for FEG-SEM analysis and Mr. Cyrille Bazin for XRD analysis (LISE, UMR8235, Sorbonne University, France). We also appreciate the Erasmus $^{+}$Program for the financial support. R. Demir-Cakan acknowledges the French Embassy for the Visiting Researcher Fellowship.

\section{ASSOCIATED CONTENT}

Supporting information is available, presenting the FEG-SEM image of the early stages of the PoPD film formation, the electrochemical impedance diagrams of PoPD films and the tables presenting the fitting parameters of the ac-electrogravimetric data.

\section{REFERENCES}

[1] Q. Zhou, G. Shi, J. Am. Chem. Soc., 138 (2016) 2868-2876.

[2] L. Li, Y. Wang, L. Pan, Y. Shi, W. Cheng, Y. Shi, G. Yu, Nano Lett., 15 (2015) 1146-1151.

[3] Z. Ma, P. Chen, W. Cheng, K. Yan, L. Pan, Y. Shi, G. Yu, Nano Lett., 18 (2018) 4570-4575.

[4] B. Kim, J. Kim, E. Kim, Macromolecules, 44 (2011) 8791-8797.

[5] Q.F. Meng, K.F. Cai, Y.X. Chen, L.D. Chen, Nano Energy, 36 (2017) 268-285.

[6] F. Shen, D. Pankratov, Q.J. Chi, Curr. Opin. Electrochem., 4 (2017) 133-144.

[7] G.A. Snook, P. Kao, A.S. Best, J. Power Sources, 196 (2011) 1-12.

[8] R.B. Ambade, S.B. Ambade, R.R. Salunkhe, V. Malgras, S.-H. Jin, Y. Yamauchi, S.-H. Lee, J. Mater. Chem. A, 4 (2016) 7406-7415.

[9] G. Wang, L. Zhang, J. Zhang, Chem. Soc. Rev., 41 (2012) 797-828.

[10] X. Lu, G. Wang, T. Zhai, M. Yu, S. Xie, Y. Ling, C. Liang, Y. Tong, Y. Li, Nano Lett., 12 (2012) 5376-5381.

[11] T. Liu, L. Finn, M. Yu, H. Wang, T. Zhai, X. Lu, Y. Tong, Y. Li, Nano Lett., 14 (2014) 2522-2527.

[12] K. Xie, J. Li, Y. Lai, Z.a. Zhang, Y. Liu, G. Zhang, H. Huang, Nanoscale, 3 (2011) 2202-2207.

[13] B.C. Kim, J.S. Kwon, J.M. Ko, J.H. Park, C.O. Too, G.G. Wallace, Synth. Met., 160 (2010) 94-98.

[14] A. Kumar, R.K. Singh, H.K. Singh, P. Srivastava, R. Singh, J. Power Sources, 246 (2014) 800-807.

[15] M. Rajesh, C.J. Raj, B.C. Kim, B.B. Cho, J.M. Ko, K.H. Yu, Electrochim. Acta, 220 (2016) 373-383.

[16] J.Y. Huang, K. Wang, Z.X. Wei, J. Mater. Chem., 20 (2010) 1117-1121.

[17] P. Du, Y. Dong, H. Kang, X. Yang, Q. Wang, J. Niu, S. Wang, P. Liu, ACS Sustain. Chem. Eng., 6 (2018) 14723-14733. 
[18] M.R. Wang, H.H. Zhang, C.Y. Wang, X.Y. Hu, G.X. Wang, Electrochim. Acta, 91 (2013) 144-151.

[19] H.P. Dai, Q.H. Wu, S.G. Sun, K.K. Shiu, J. Electroanal. Chem., 456 (1998) 47-59.

[20] T. Tonosaki, T. Oho, K. Isomura, K. Ogura, J. Electroanal. Chem., 520 (2002) 89-93.

[21] J.L. Olmedo-Martinez, B.I. Farias-Mancilla, A. Vega-Rios, E.A. Zaragoza-Contreras, J. Power Sources, 366 (2017) 233-240.

[22] Jaidev, S. Ramaprabhu, J. Mater. Chem., 22 (2012) 18775-18783.

[23] C. Yuan, X. Liu, M. Jia, Z. Luo, J. Yao, J. Mater. Chem. A, 3 (2015) 3409-3415.

[24] X. Tu, Q. Xie, C. Xiang, Y. Zhang, S. Yao, J. Phys. Chem. B, 109 (2005) 4053-4063.

[25] K. Martinusz, E. Czirok, G. Inzelt, J. Electroanal. Chem., 379 (1994) 437-444.

[26] M.D. Levi, L. Daikhin, D. Aurbach, V. Presser, Electrochem. Commun., 67 (2016) 16-21.

[27] M.D. Levi, N. Shpigel, S. Sigalov, V. Dargel, L. Daikhin, D. Aurbach, Electrochim. Acta, 232 (2017) 271284.

[28] Z.F. Lin, P.L. Taberna, P. Simon, Curr. Opin. Electrochem., 9 (2018) 18-25.

[29] N. Shpigel, M.R. Lukatskaya, S. Sigalov, C.E. Ren, P. Nayak, M.D. Levi, L. Daikhin, D. Aurbach, Y. Gogotsi, ACS Energy Lett., 2 (2017) 1407-1415.

[30] N. Shpigel, M.D. Levi, S. Sigalov, O. Girshevitz, D. Aurbach, L. Daikhin, N. Jackel, V. Presser, Angew. Chem.-Int. Edit., 54 (2015) 12353-12356.

[31] C. Gabrielli, J.J. Garcia-Jareno, M. Keddam, H. Perrot, F. Vicente, J. Phys. Chem. B, 106 (2002) 31823191.

[32] C. Gabrielli, J.J. Garcia-Jareno, M. Keddam, H. Perrot, F. Vicente, J. Phys. Chem. B, 106 (2002) 31923201.

[33] C.R. Arias, C. Debiemme-Chouvy, C. Gabrielli, C. Laberty-Robert, A. Pailleret, H. Perrot, O. Sel, J. Phys. Chem. C, 118 (2014) 26551-26559.

[34] W. Gao, C. Debiemme-Chouvy, M. Lahcini, H. Perrot, O. Sel, Anal. Chem., (2019).

[35] F. Escobar-Teran, H. Perrot, O. Sel, J. Phys. Chem. C, (2019).

[36] W.L. Gao, O. Sel, H. Perrot, Electrochim. Acta, 233 (2017) 262-273.

[37] H. Goubaa, F. Escobar-Teran, I. Ressam, W.L. Gao, A. El Kadib, I.T. Lucas, M. Raihane, M. Lahcini, H. Perrot, O. Sel, J. Phys. Chem. C, 121 (2017) 9370-9380.

[38] W.L. Gao, H. Perrot, O. Sel, Phys. Chem. Chem. Phys., 20 (2018) 27140-27148.

[39] H.X. Zhang, Y.D. Cao, M.O.L. Chee, P. Dong, M.X. Ye, J.F. Shen, Nanoscale, 11 (2019) 5807-5821.

[40] J.M. Li, A. Levitt, N. Kurra, K. Juan, N. Noriega, X. Xiao, X.H. Wang, H.Z. Wang, H.N. Alshareef, Y. Gogotsi, Energy Storage Mater., 20 (2019) 455-461.

[41] M. Tahir, L. He, W.A. Haider, W. Yang, X.F. Hon, Y.Q. Guo, X.L. Pan, H. Tang, Y.X. Li, L.Q. Mai, Nanoscale, 11 (2019) 7761-7770.

[42] G. Sauerbrey, Zeitschrift für Physik, 155 (1959) 206-222.

[43] K. Bizet, C. Gabrielli, H. Perrot, Appl. Biochem. Biotechnol., 89 (2000) 139.

[44] X.H. Zhang, S.M. Wang, J. Wu, X.J. Liu, J. Appl. Polym. Sci., 104 (2007) 1928-1932.

[45] C. Barbero, J.J. Silber, L. Sereno, J. Electroanal. Chem., 263 (1989) 333-352.

[46] N. Oyama, T. Ohsaka, K. Chiba, K. Takahashi, Bull. Chem. Soc. Jpn., 61 (1988) 1095-1101.

[47] J.J. Garcia-Jareno, C. Gabrielli, H. Perrot, Electrochem. Commun., 2 (2000) 195-200.

[48] Augustus W. Lang, J.F. Ponder, A.M. Österholm, N.J. Kennard, R.H. Bulloch, J.R. Reynolds, J. Mater. Chem. A, 5 (2017) 23887-23897.

[49] X.Y. Lang, A. Hirata, T. Fujita, M.W. Chen, Nature Nanotech., 6 (2011) 232-236.

[50] S.S. Shinde, G.S. Gund, D.P. Dubal, S.B. Jambure, C.D. Lokhande, Electrochim. Acta, 119 (2014) 1-10.

[51] E. Karaca, N.O. Pekmez, K. Pekmez, Electrochim. Acta, 147 (2014) 545-556.

[52] L. Chen, L.J. Sun, F. Luan, Y. Liang, Y. Li, X.X. Liu, J. Power Sources, 195 (2010) 3742-3747.

[53] K.L. Zhou, H. Wang, J.T. Jiu, J.B. Liu, H. Yan, K. Suganuma, Chem. Eng. J., 345 (2018) 290-299.

[54] M.K. Singh, K. Jörg, H. Horst, J. Electrochem. Soc., 162 (2015) A 1196-A 1201. 
[55] B. Yao, L. Huang, J. Zhang, X. Gao, J.B. Wu, Y.L. Cheng, X. Xiao, B. Wang, Y. Li, J. Zhou, Adv. Mater., 28 (2016) 6353-6358.

[56] J. Wang, C. Wu, P. Wu, X. Li, M. Zhang, J. Zhu, Phys. Chem. Chem. Phys., 19 (2017) 21165-21173.

[57] H. Yadegari, H. Heli, A. Jabbari, J. Solid State Electrochem., 17 (2013) 2203-2212.

[58] W.J. Yang, H.H. Zhou, Z. Huang, H.X. Li, C.P. Fu, L. Chen, M.B. Li, S.S. Liu, Y.F. Kuang, Electrochim. Acta, 245 (2017) 41-50.

[59] M.R. Wang, H.H. Zhang, C.Y. Wang, G.X. Wang, Electrochim. Acta, 106 (2013) 301-306.

[60] S.R. Sivakkumar, R. Saraswathi, J. Applied Electrochem., 34 (2004) 1147-1152.

\section{Highlights}

- Poly(ortho-phenylenediamine) (PoPD) exhibits excellent stability over 8000 cycles

- Charge compensation of PoPD occurs with the participation of multiple species

- Each species' interfacial transfer takes place at a different temporal scale

- Significant role of $\mathrm{H}^{+}$to the charge compensation is unravelled

\section{Table of Contents/Abstract Graphics}

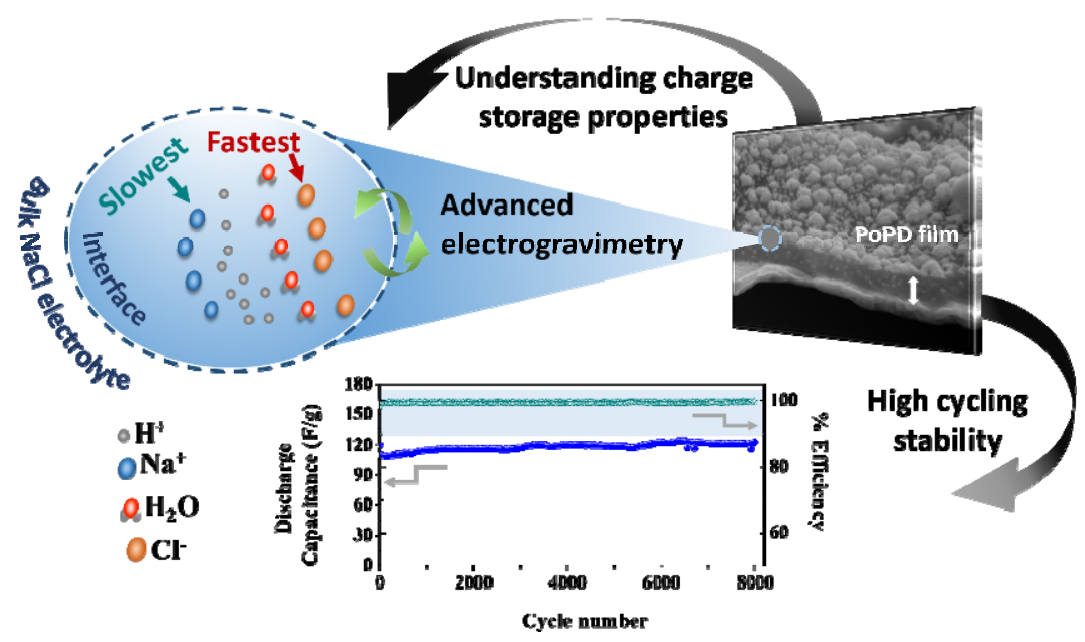




\section{Supporting information for:}

\section{Correlation between the interfacial ion dynamics and charge storage properties of poly(ortho-phenylenediamine) electrodes exhibiting high cycling stability}

El Mahdi Halim ${ }^{\dagger, \ddagger}$, Rezan Demir-Cakan ${ }^{\S, ¥}$, Hubert Perrot $^{\dagger}$, Mama El Rhazi ${ }^{*}$, ,Ozlem Sel $^{*, \dagger}$

† Sorbonne Université, CNRS, Laboratoire Interfaces et Systèmes Electrochimiques, LISE, 75005 Paris, France

* University of Hassan II of Casablanca, Faculty of Sciences and Technology, Laboratory of Materials, Membranes and Environment -BP 146, 20650 Mohammedia, Morocco

$\S$ Institute of Nanotechnology, Gebze Technical University, 41400 Gebze, Kocaeli, Turkey

¥ Department of Chemical Engineering, Gebze Technical University, 41400 Gebze, Kocaeli, Turkey

* Corresponding authors: Email: ozlem.sel@upmc.fr

Email: elrhazim@hotmail.com 


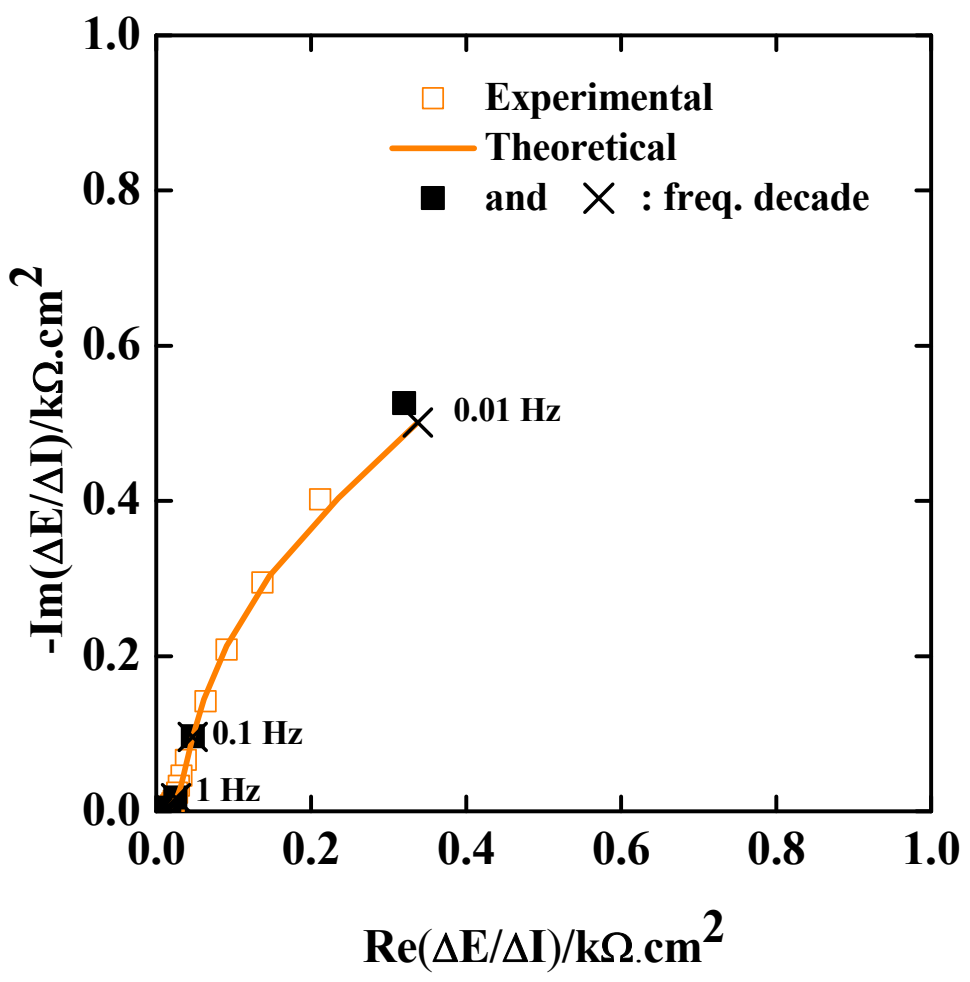

Figure SI-1: Electrochemical impedance diagram $(\Delta E / \Delta I(\omega))$ at $-0.25 \mathrm{~V}$ of the PoPD film electrodeposited on a gold coated quartz resonator and measured in $0.5 \mathrm{M} \mathrm{NaCl}$ solution at $\mathrm{pH}=2$. 


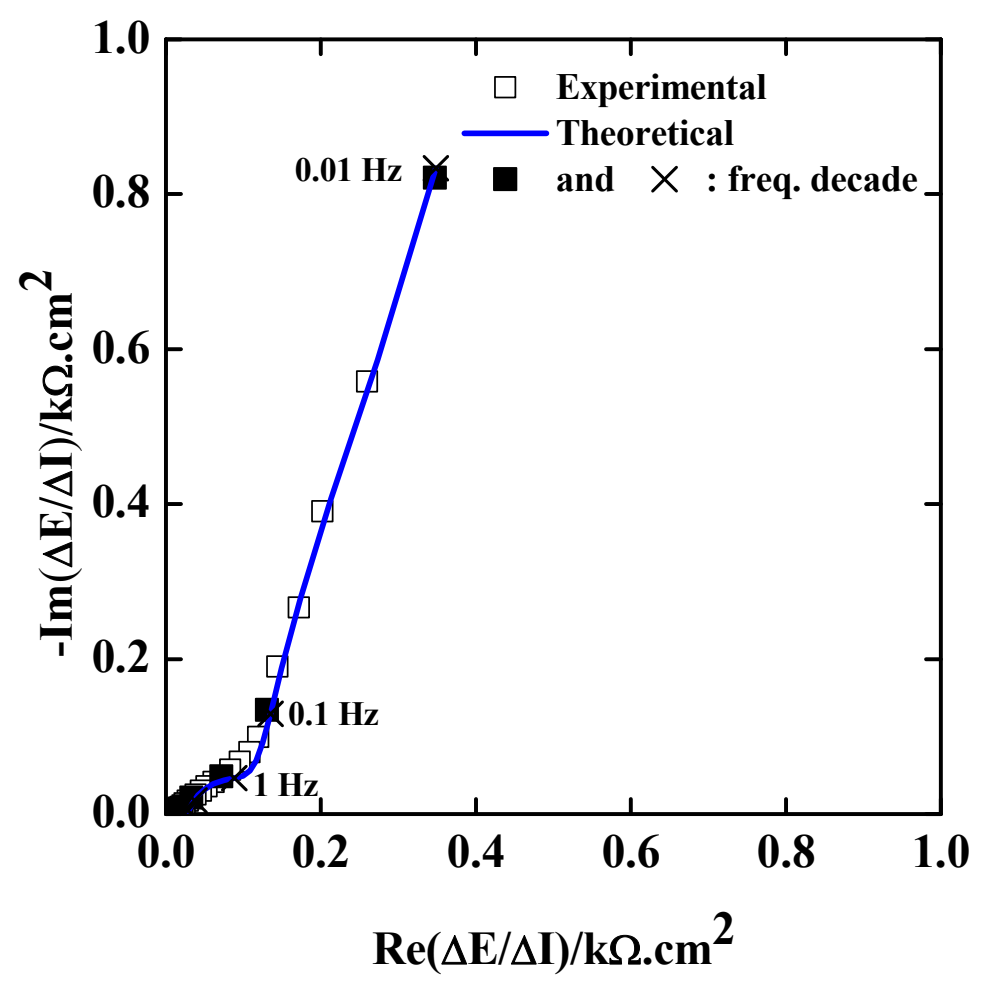

Figure SI-2: Electrochemical impedance diagram $(\Delta E / \Delta I(\omega))$ at $0.05 \mathrm{~V}$ of the PoPD film electrodeposited on a gold coated quartz resonator and measured in $0.5 \mathrm{M} \mathrm{NaCl}$ solution at $\mathrm{pH}=2$. 


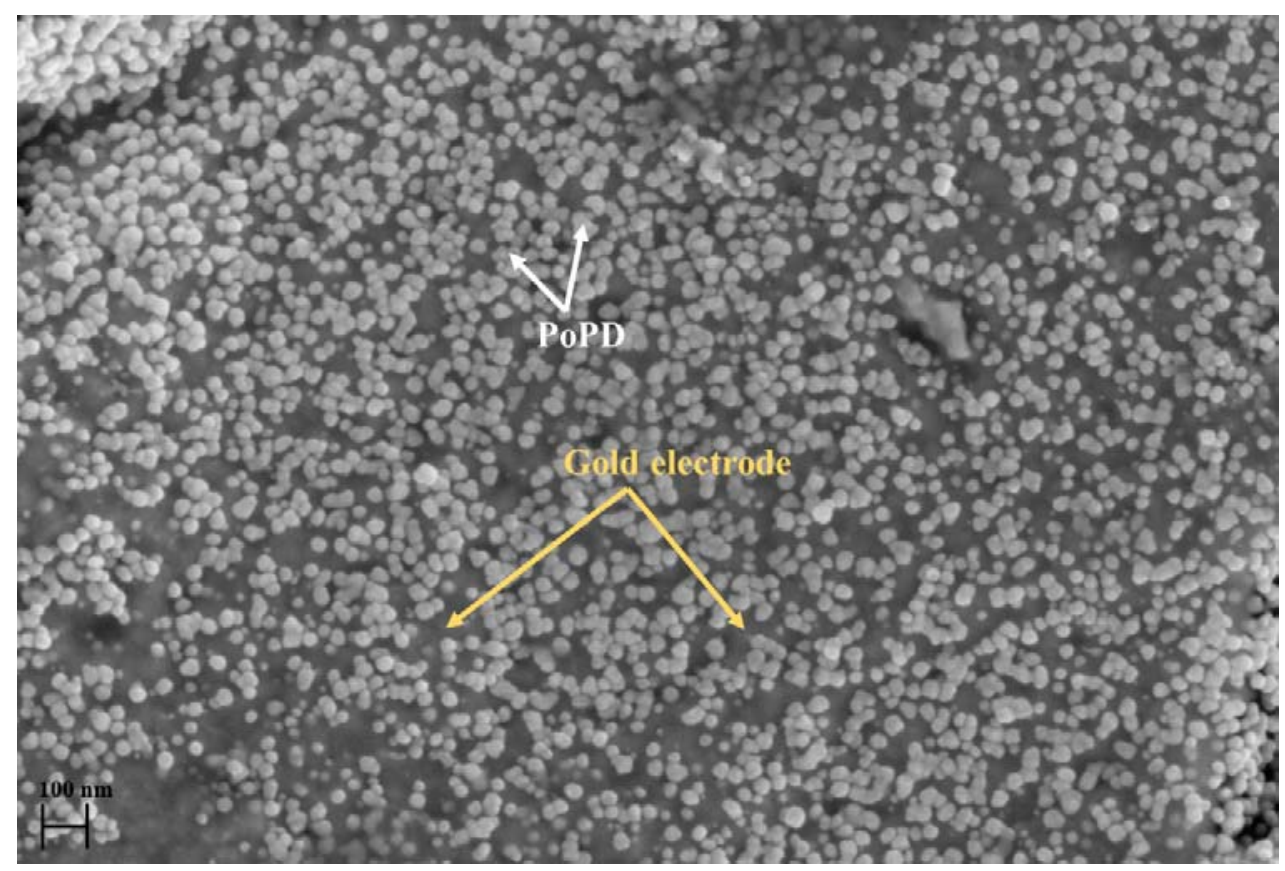

Figure SI-3: FEG-SEM image of the early stage of the PoPD thin film formation on the gold electrode of a quartz resonator after $50 \mathrm{CV}$ cycles. 
Table SI-1: Estimated values for $\boldsymbol{K}_{\boldsymbol{i}}$ (kinetics of transfer) and $\boldsymbol{G}_{\boldsymbol{i}}$ (the inverse of the transfer resistance), $\boldsymbol{R}_{\boldsymbol{i}}$ (transfer resistance) and $\boldsymbol{f}_{\boldsymbol{i}}$ (characteristic frequency) parameters extracted from the fitting results of ac-electrogravimetry measurements of the PoPD film electrodeposited on a gold coated quartz resonator and measured at $-0.05 \mathrm{~V}$ et $-0.25 \mathrm{~V} v \mathrm{sg} / \mathrm{AgCl}$, measured in $0.5 \mathrm{M} \mathrm{NaCl}$ at $\mathrm{pH}=2$.

\begin{tabular}{|c|c|c|c|c|c|c|}
\hline $\mathrm{pH}=2$ & $\begin{array}{c}\text { Species } \\
\text { identification } \\
\text { (i) }\end{array}$ & $\begin{array}{c}\boldsymbol{M}_{\boldsymbol{i}} \\
\left(\mathrm{g} \cdot \mathrm{mol}^{-1}\right)\end{array}$ & $\begin{array}{c}\boldsymbol{K}_{i} \\
\left(\mathrm{~cm} \cdot \mathrm{s}^{-1}\right)\end{array}$ & $\begin{array}{c}\boldsymbol{G}_{\boldsymbol{i}} \\
\left(\mathrm{mol} . \mathrm{s}^{-1} \cdot \mathrm{cm}^{-2} \cdot \mathrm{V}^{-1}\right)\end{array}$ & $\begin{array}{c}\boldsymbol{R} \boldsymbol{t}_{\boldsymbol{i}}=\mathbf{1 / F \boldsymbol { G } _ { \boldsymbol { i } }} \\
\left(\Omega . \mathrm{cm}^{2}\right)\end{array}$ & $\begin{array}{c}\boldsymbol{f}_{\boldsymbol{i}}=\boldsymbol{K}_{i} / \boldsymbol{\pi} \boldsymbol{d}_{f} \\
(H z)\end{array}$ \\
\hline \multicolumn{7}{|c|}{ at $-0.05 \mathrm{~V}$} \\
\hline$a$ & $\mathrm{Cl}^{-}$ & 35 & $37.70 \times 10^{-5}$ & $-2.45 \times 10^{-7}$ & 42.30 & 12.01 \\
\hline$S$ & $\mathrm{H}_{2} \mathrm{O}$ & 18 & $1.10 \times 10^{-5}$ & $0.22 \times 10^{-7}$ & 471.10 & 0.35 \\
\hline$c 1$ & $\mathrm{Na}^{+}$ & 23 & $0.16 \times 10^{-5}$ & $0.02 \times 10^{-7}$ & 4391.64 & 0.05 \\
\hline$c 2$ & $\mathrm{H}^{+}$ & 1 & $0.63 \times 10^{-5}$ & $0.78 \times 10^{-7}$ & 132.03 & 0.20 \\
\hline \multicolumn{7}{|c|}{ at $-0.25 \mathrm{~V}$} \\
\hline$a$ & $\mathrm{Cl}^{-}$ & 35 & $53.40 \times 10^{-5}$ & $-12.90 \times 10^{-7}$ & 7.46 & 17.01 \\
\hline$s$ & $\mathrm{H}_{2} \mathrm{O}$ & 18 & $2.23 \times 10^{-5}$ & $0.11 \times 10^{-7}$ & 933.58 & 0.71 \\
\hline$c 1$ & $\mathrm{Na}^{+}$ & 23 & $1.57 \times 10^{-5}$ & $0.78 \times 10^{-7}$ & 244.38 & 0.30 \\
\hline$c 2$ & $\mathrm{H}^{+}$ & 1 & $2.20 \times 10^{-5}$ & $2.20 \times 10^{-7}$ & 47.13 & 0.70 \\
\hline
\end{tabular}

Table SI-2: Papers about Polyaniline and Polypyrrole.

\begin{tabular}{|l|l|l|l|l|l|}
\hline Material & $\begin{array}{l}\text { Scan Rate } \\
\text { or Current } \\
\text { density }\end{array}$ & Electrolyte & $\begin{array}{l}\text { Specific } \\
\text { capacitance }\end{array}$ & $\begin{array}{l}\text { Capacity retention } \\
\text { (number of cycles) }\end{array}$ & reference \\
\hline PPy & $50 \mathrm{mV} . \mathrm{s}^{-1}$ & $\mathrm{H}_{2} \mathrm{SO}_{4}(0.5 \mathrm{M})$ & $230 \mathrm{~F} . \mathrm{g}^{-1}$ & $87 \%(1000)$ & 1 \\
\hline PPy & $100 \mathrm{mV} . \mathrm{s}^{-1}$ & $\mathrm{H}_{2} \mathrm{SO}_{4}$ & $215 \mathrm{~F} \cdot \mathrm{g}^{-1}$ & & 2 \\
\hline PPy & $50 \mathrm{mV} . \mathrm{s}^{-1}$ & $\mathrm{H}_{2} \mathrm{SO}_{4}(0.5 \mathrm{M})$ & $250 \mathrm{~F} \cdot \mathrm{g}^{-1}$ & $82 \%(1000)$ & 3 \\
\hline
\end{tabular}




\begin{tabular}{|l|l|l|l|l|l|}
\hline PPY & $3{\mathrm{~A} \cdot \mathrm{g}^{-1}}^{\mathrm{KCl}}(1 \mathrm{M})$ & $576 \mathrm{~F} \cdot \mathrm{g}^{-1}$ & $82 \%(1000)$ & 4 \\
\hline PPy-NW & $20 \mathrm{mv} / \mathrm{s}$ & $\mathrm{H}_{2} \mathrm{SO}_{4}(1 \mathrm{M})$ & $110 \mathrm{~F} \cdot \mathrm{g}^{-1}$ & $\sim 25 \%(5000)$ & 5 \\
\hline PANI-NW & $20 \mathrm{mv} / \mathrm{s}$ & $\mathrm{H}_{2} \mathrm{SO}_{4}(1 \mathrm{M})$ & $191 \mathrm{~F} \cdot \mathrm{g}^{-1}$ & $\sim 42 \%(5000)$ & 5 \\
\hline PANI & $50 \mathrm{mV} \cdot \mathrm{s}^{-1}$ & $\mathrm{H}_{2} \mathrm{SO}_{4}(0.5 \mathrm{M})$ & $451 \mathrm{~F} \cdot \mathrm{g}^{-1}$ & & 6 \\
\hline PANI & $4 \mathrm{~mA} \cdot \mathrm{cm}^{-2}$ & $\mathrm{NaNO}_{3}(1 \mathrm{M})$ & $150 \mathrm{~F} \cdot \mathrm{g}^{-1}$ & & 7 \\
\hline PANI & $20 \mathrm{mV} \cdot \mathrm{s}^{-1}$ & $\mathrm{H}_{2} \mathrm{SO}_{4}(0.5 \mathrm{M})$ & $192 \mathrm{~F} \cdot \mathrm{g}^{-1}$ & $67 \%(5000)$ & 8 \\
\hline
\end{tabular}
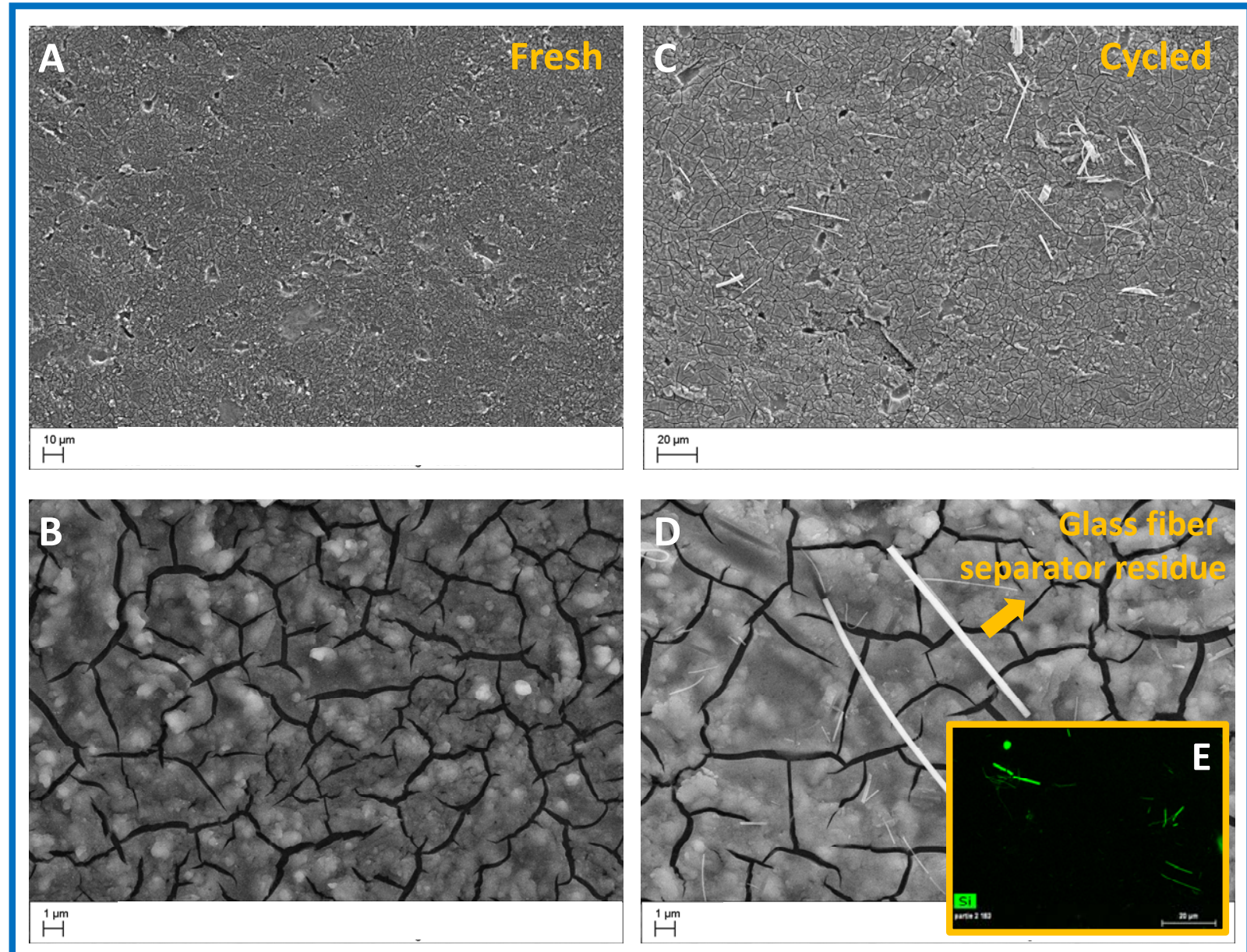

Figure SI-4: The FEG-SEM images of the fresh (A and B) and after 8000 cycles in Swagelok cells in $0.5 \mathrm{M} \mathrm{NaCl}, \mathrm{pH}=2(\mathrm{C}$ and $\mathrm{D})$. The EDX spectra of the cycled electrode surface indicating the presence of the glass fiber residue originating from the separator used in Swagelok cells. 

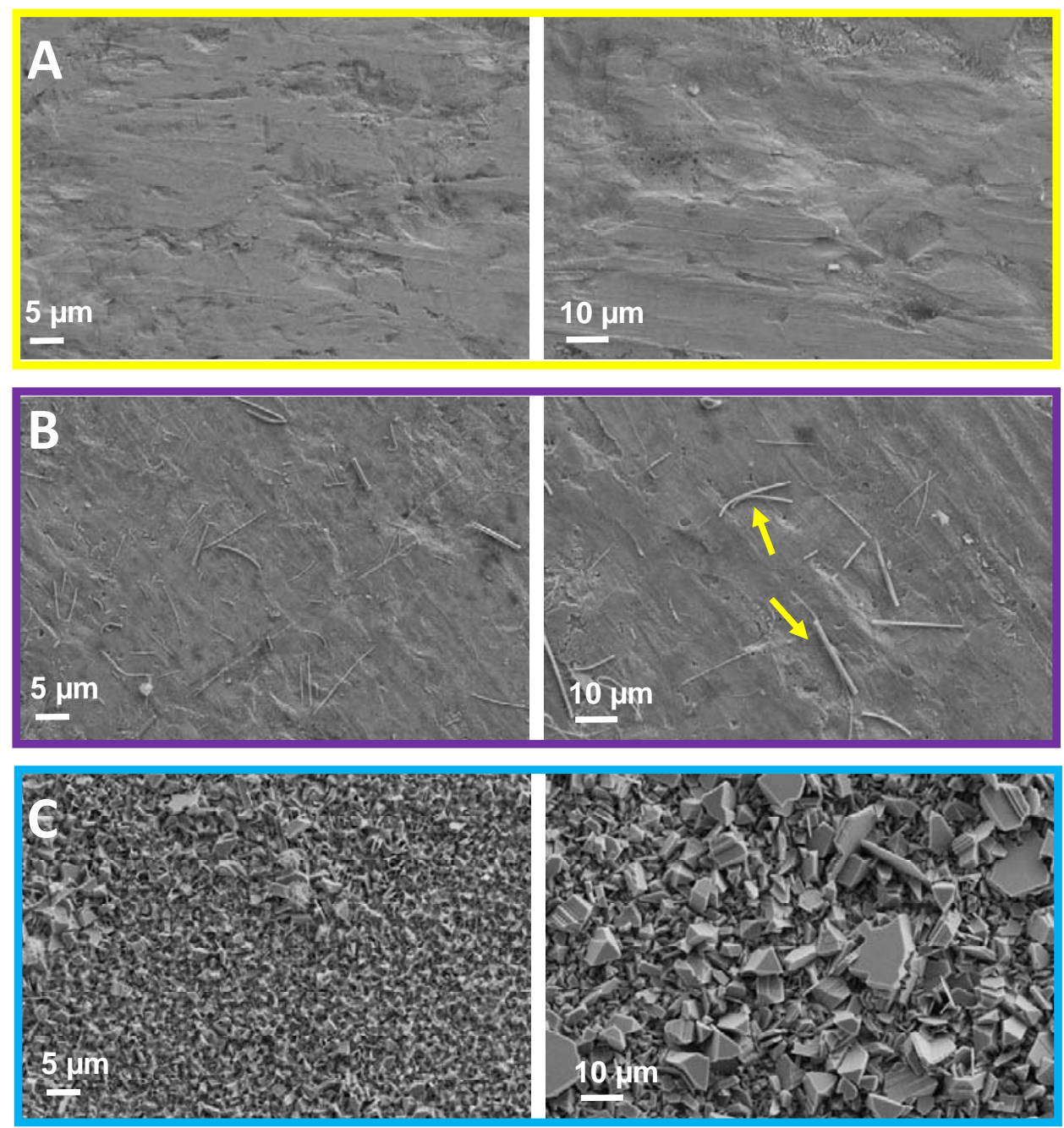

Figure SI-5 The FEG-SEM images of the fresh $\mathrm{Zn}$ metal (panel A) and after 8000 cycles in Swagelok cells in $0.5 \mathrm{M} \mathrm{NaCl}, \mathrm{pH}=2$ (panel B) (yellow arrows indicates the residual glass fibers). The panel $\mathrm{C}$ shows images after immersing the $\mathrm{Zn}$ metal in the electrolyte for one week of resting period (that is the time spent to reach 8000 cycles during galvanostatic cycling).

The FEG-SEM images of the pristine Zn (Figure SI-5, panel A) reveals rather rough surface topology that was not significantly changed upon 8000 cycles in the presence of $0.5 \mathrm{M} \mathrm{NaCl}$, ( $\mathrm{pH}: 2)$ electrolyte (Figure SI-5, panel B). However, some remaining fibers were also observed on $\mathrm{Zn}$ foil originating from the separator used in the Swagelok tests. On the other hand, after immersing the $\mathrm{Zn}$ metal in the electrolyte for one week of resting period (Figure SI, panel C), hexagonal-like crystals were observed on the surface that is a typical phenomenon when $\mathrm{Zn}$ is electro-coated in the presence of chloride $(9,10)$. As a whole, the amount of electrolyte matters 
on such dramatic morphological changes. In our study, during two electrode Swagelok cell measurements, only $0.15 \mathrm{ml}$ of the electrolyte has been used and in that way we have limited the morphological changes, at least for the 8000 GCD cycles under the conditions of our study.

\section{References}

(1) Sujata S. Shinde et al, Morphological modulation of polypyrrole thin films through oxidizing agents and their concurrent effect on supercapacitor performance. Electrochimica Acta 119 (2014) $1-10$.

(2) Erhan Karaca et al, Galvanostatic deposition of polypyrrole in the presence of tartaric acid for electrochemical supercapacitor. Electrochimica Acta 147 (2014) 545-556.

(3) SujataS.Shinde., et al., Morphological modulation of polypyrrole thin films through oxidizing agents and their concurrent effect on supercapacitor performance. Electrochimica Acta, 119 (2014) 1-10.

(4) Mei Li. et al., Intrinsic flexible polypyrrole film with excellent electrochemicalperformance. J Mater Sci: Mater Electron (2015) 26: 4875.

(5) Liu, T., et al., Polyaniline and Polypyrrole Pseudocapacitor Electrodes with Excellent Cycling Stability. Nano Letters, 2014. 14(5): p. 2522-2527.

(6) KaiLing Zhou et al, Polyaniline Films with Modified Nanostructure for Bifunctional Flexible Multicolor Electrochromic and Supercapacitor Applications. Chemical Engineering Journal, 2018, 345, 290-299.

(7) Liang Chen et al, Synthesis and pseudocapacitive studies of composite films of polyaniline and manganese oxide nanoparticles. Journal of Power Sources 195 (2010) 3742-3747.

(8) Sagar H. Patil. et al., To form layer by layer composite film in view of its application as supercapacitorelectrode by exploiting the techniques of thin films formation just around the corner. Electrochimica Acta, 2018, doi: 10.1016/j.electacta.2018.01.165.

(9) G. Barceló, E. García, M. Sarret, C. Müller, J. Pregonas, Journal of Applied Electrochemistry, 28 (1998) 1113-1120.

(10) H.M. Wang, T.J. O'Keefe, Journal of Applied Electrochemistry, 24 (1994) 900-905. 